The author(s) shown below used Federal funds provided by the U.S. Department of Justice and prepared the following final report:

Document Title: Unpacking the Influence of Neighborhood Context and Antisocial Propensity on Violent Victimization of Children and Adolescents in Chicago

Author: $\quad$ Chris L. Gibson, Ph.D.

Document No.: 237731

Date Received: $\quad$ February 2012

Award Number: $\quad$ 2009-IJ-CX-0041

This report has not been published by the U.S. Department of Justice. To provide better customer service, NCJRS has made this Federallyfunded grant final report available electronically in addition to traditional paper copies.

Opinions or points of view expressed are those of the author(s) and do not necessarily reflect the official position or policies of the U.S.

Department of Justice. 


\title{
Unpacking the Influence of Neighborhood Context and Antisocial Propensity on Violent Victimization of Children and Adolescents in Chicago
}

\author{
A Final Report Submitted to the National Institute of Justice
}

Award No: 2009-IJ-CX-0041

Chris L. Gibson, Ph.D.

Department of Sociology and Criminology \& Law

University of Florida

This project was supported by Award No: 2009-IJ-CX-0041 awarded by the National Institute of Justice, Office of Justice Programs, U.S. Department of Justice. Opinions, findings, and conclusions or recommendations expressed in this publication/program/ exhibition are those of the author(s) and do not necessarily reflect those of the Department of Justice. 


\title{
ABSTRACT \\ Unpacking the Influence of Neighborhood Context and Antisocial Propensity on Violent Victimization of Children and Adolescents in Chicago
}

\author{
Chris L. Gibson, Ph.D. \\ University of Florida
}

This research combines social disorganization and self-control theories to understand violent victimization among children and adolescents. In doing so, several research questions are investigated to explore the independent and interactive influences that neighborhood disadvantage and low self-control have on violent victimization risk.

Data from the 9,12, and 15-year old cohorts of the Longitudinal Cohort Study in the Project on Human Development in Chicago Neighborhoods (PHDCN-LCS) were used in this study. Data analyzed were from self-reports of children, adolescents, and their primary caregivers during waves 1 and 2 of the longitudinal data collection effort. In addition, neighborhood structural characteristics from the U.S. Census were also analyzed.

Results from a combination of hierarchical generalized linear models and multivariate logistic regression models with robust standard errors revealed that violent victimization did not significantly vary across neighborhoods, and independent of various behavioral and lifestyle choices made by children and adolescents, low self-control increased the risk for becoming a victim of violence. Additionally, choices made by them also influenced their risk of violent victimization; those who reported engaging in violent offending, spending more time in unstructured activities, and having more delinquent peers had a higher risk of being a victim of violence. Further analysis shows that the association between low self-control and violent victimization risk varies across levels of neighborhood concentrated disadvantage in which youth live; low self-control's influence in the most disadvantaged neighborhoods dissipated while it was amplified for those living in the least disadvantaged neighborhoods. Unstructured socializing with peers was the only factor that significantly influenced violent victimization risk across low, medium and high disadvantaged neighborhoods. Findings are consistent with a "social push" perspective, which suggests that disadvantaged environments provide social pressures that may override the influence of individual differences on vulnerability to violent victimization.

Implications of this study's findings are discussed as they relate to policy, prevention and theory; while also setting forth a research agenda on neighborhoods, antisocial traits, and violent victimization risk for future research. 


\section{TABLE OF CONTENTS}

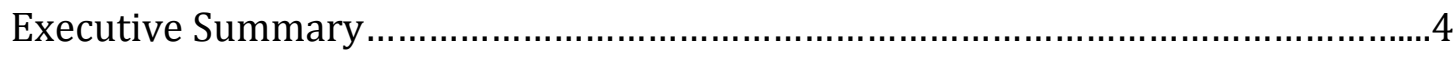

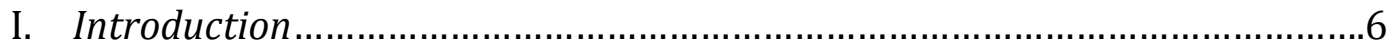

Neighborhood Context, Crime, and Criminal Victimization................9

Low Self-Control, Lifestyles, and Violent Victimization.....................14

The Current Study .........................................................................17

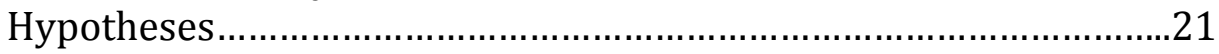

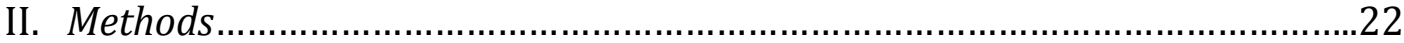

The Project on Human Development in Chicago Neighborhoods.................22

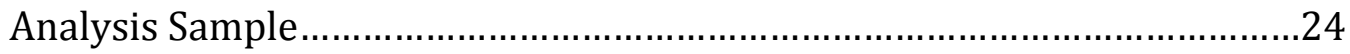

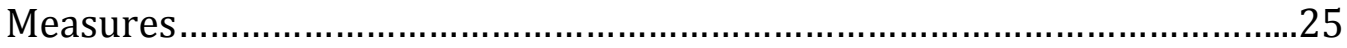

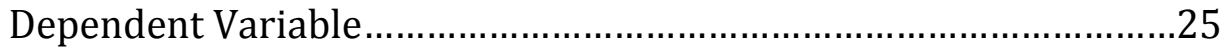

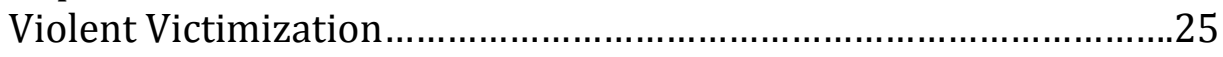

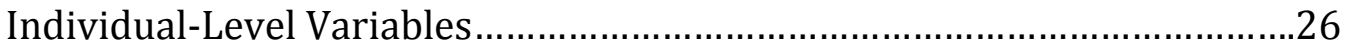

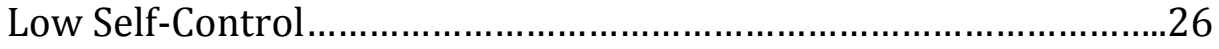

Family Attachment and Support.................................................27

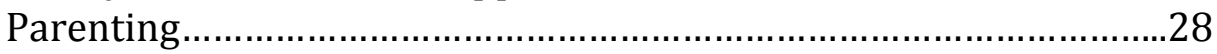

Lifestyles, Situational, and Behavioral Variables.............................29

Demographic Characteristics..........................................................30

Neighborhood-Level Variables....................................................................31

Concentrated Disadvantage .............................................................31

Violent Crime..............................................................................

Neighborhood Social Process........................................................31

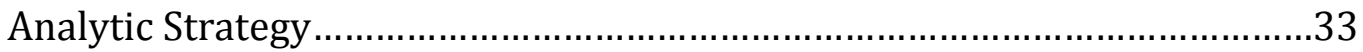

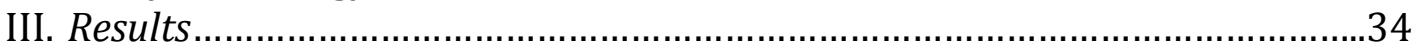

Differences between Victims of Violence and Non-Victims.............................34

Type and Context of Violent Victimization...................................................36

Multivariate Analysis Predicting Violent Victimization...................................38

Neighborhoods Disadvantage, Low Self-Control, and

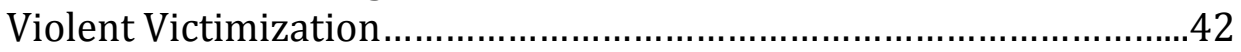

Conditional Probabilities of Violent Victimization for the Full Model............45

Conditional Probabilities of Violent Victimization: Differing Influences

of Low Self-Control across Neighborhoods...............................................50

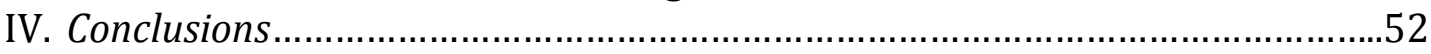

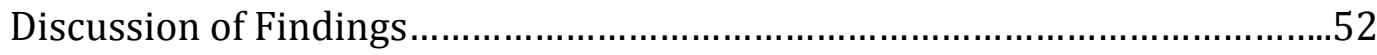

Implications for Policy and Practice...............................................................56

Study Limitations and Future Research.........................................................61

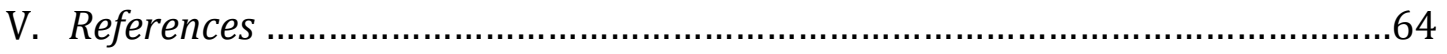

VI. Dissemination of Research Findings ................................................................74

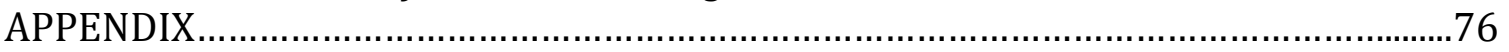

This document is a research report submitted to the U.S. Department of Justice. This report has not been published by the Department. Opinions or points of view expressed are those of the author(s) and do not necessarily reflect the official position or policies of the U.S. Department of Justice. 


\section{EXECUTIVE SUMMARY}

Compared to any other age group in the United States, adolescence is a period of development where individuals are most at risk for becoming victims of violence. Violent victimization increases from ages 12 to 15 and increases even more between 16 to 19 years of age. In fact, those between the ages of 12 and 17 have historically experienced the highest rates of violent victimization compared to other age groups (Rennison, 2002). The increased risk of violent victimization during this period is not due to chance, but is rather determined by the context in which individuals reside, the activities they choose to engage in, and the individual characteristics that make them different from each other. It is imperative to identify neighborhood and individual-level factors that will decrease the risk of violent victimization among youth.

Guided by both social disorganization and self-control theories, this study is an effort to empirically illustrate the independent and interactive influences of neighborhood context and one measure of antisocial propensity, e.g., low selfcontrol, on violent victimization. This project is unique in that it synthesizes a large amount of research toward the goal of understanding the link between an important social context and individual trait for understanding the risk of violent victimization. Youth who live in disadvantage neighborhoods may be at increased risk for violent victimization due to a host of reasons that include proximity to offenders, a lack of informal social controls or capable guardians, and street norms that encourage violence. From a self-control perspective, adolescents who have lower self-control are more at risk for violent victimization because of their lifestyles and personal characteristics that make them highly vulnerable to crime (Schreck, 1999). Possessing characteristics such as impulsivity and risk seeking, which are indicative of low self-control, can lead individuals into situations that put them in closer proximity to offenders. While research supports these two correlates of violent victimization, much less is known about if and how they interact to determine violent victimization risk.

Data from 1,889 youth from the 9, 12, and 15 year-old cohorts of the PHDCNLCS, an interdisciplinary study on how the contexts in which children and adolescents reside contribute to their behavior and psychological development, were analyzed to test hypotheses in the current study. Violent victimization is predicted using individual-level predictors from waves 1 and 2 of the longitudinal cohort study. Additionally, 1990 U.S. Census data were used to measure neighborhood-level structure of the 80 neighborhood clusters, i.e., aggregations of 1 to 3 census tracts. Through combining data from the longitudinal cohort study and the 1990 U.S. Census, the PHDCN is appropriate for assessing the intersection between neighborhood and individual-level factors on violent victimization experiences among children and adolescents.

Several findings from this study are particularly noteworthy. First, findings confirm work by others (Higgins, Jennings, Tewksbury, \& Gibson, 2010; Schreck, 1999; Schreck, Wright, \& Miller, 2002) showing that youth with lower self-control

are at more risk for becoming victims of violence. This relationship remained after controlling for situational, behavioral, and lifestyle characteristics that are 
commonly chosen by low self-control individuals and that also influence their vulnerability to violence. Second, and running counter to research on neighborhoods and victimization among adults, adolescents residing in the most disadvantaged neighborhoods were not significantly more likely to experience violent victimization compared to those in the lowest disadvantaged neighborhoods. Third, delinquent peers and prior involvement in violent offending were conditioned by neighborhood context; youth reporting more delinquent peers and prior involvement in violent offending were at increased risk for being victims of violence in less disadvantaged neighborhoods but not in the most disadvantaged ones. Fourth, low self-control's influence on violent victimization was conditioned by neighborhood type. Low self-control had a statistically significant influence on violent victimization for youth residing in the least disadvantaged neighborhoods; however, low self-control did not influence violent victimization among those living in the most disadvantaged neighborhoods. Finally, time spent in unstructured activities was the only variable to have a statistically significant influence on violent victimization across each level of the neighborhood concentrated disadvantage variable.

To date, most research addressing the prevention of violent victimization among youth has focused on lifestyle factors, routine activities (e.g., suitable targets and guardianship) and target hardening, but often ignores the multilayered context of risk, i.e., how factors at both the individual and contextual levels interact to shape violent victimization risk. Findings from this study have several potential implications for reducing violent victimization. First, because low self-control has such far-reaching influences on a spectrum of social and health-related outcomes across developmental stages, it is important to identify early childhood precursors of low self-control to prevent the accumulation of negative outcomes that are related to this trait, one of which is vulnerability to violence. Prevention strategies should target early childhood socialization and parenting practices to prevent the development of low self-control. Second, although early prevention is important, promising research suggests that self-control is susceptible to change in later stages of one's life-course (Burt, Simon, \& Simons, 2006; Moffitt et al., 2011). As such, prevention and intervention efforts should target different developmental periods for training that encourages individuals to make better decisions; to seriously consider how their actions affect others; and to more generally think about the consequences of their behavior. Given the broader and long-term negative consequences that stem from this trait (Moffitt et al. 2011), opportunities to change self-control among youth in more disadvantaged environments are also important; especially since families residing in such neighborhoods may have limited resources to do so. It will also be important to identify and address the environmental forces that override the influence of individual differences on vulnerability for violent victimization in disadvantaged neighborhoods. Finally, since unstructured time spent with peers was the only factor that exhibited a statistically significant relationship with violent victimization across levels of neighborhood disadvantage, parents in high, medium, and low disadvantaged neighborhoods may have success at reducing their children's violent victimization by minimizing the unstructured activities they engage in with peers.

This document is a research report submitted to the U.S. Department of Justice. This report has not been published by the Department. Opinions or points of view expressed are those of the author(s) and do not necessarily reflect the official position or policies of the U.S. Department of Justice. 


\section{INTRODUCTION}

Compared to any other age group in the United States, adolescence is a period of development where individuals are at the most risk for becoming victims of violence. This trend is confirmed by findings from the National Crime Victimization Survey, which show a strong relationship between age and violent victimization. The risk of becoming a victim of violence increases from ages 12 to 15 and even more between 16 to 19 years of age. In fact, youth between the ages of 12 and 17 have historically experienced the highest rates of violent victimization compared to other age groups (Rennison, 2002). Thus, it is crucial to identify contextual and individual factors that can decrease the risk of violent victimization among youth.

The increased risk of violent victimization during late childhood and adolescence is not due to chance. Vulnerability to violence is influenced by the context in which individuals reside, the activities they choose to engage in, and the individual characteristics that make them different from each other (Gibson, Morris, \& Beaver, 2009; Leventhal \& Brooks-Gunn, 2003; Maimon \& Browning, 2010; Mayer \& Jencks, 1989; Schreck et al., 2002; Sharkey, 2006; Wilcox-Rountree, Land, \& Miethe, 1994). Historically, situational and contextual theories have had the largest influence on explaining personal and violent victimization (Cohen \& Felson, 1979; Hindelang, Gottfredson, \& Garofalo, 1978). Ranging from lifestyle choices to the imposed structural conditions of neighborhoods, a primary focus in research has been on how environments encountered by people can put them at risk for becoming a victim of crime. On the other hand, studies show that individual traits increase can increase a person's risk for being victimized. In particular, low self- 
control-defined as the likelihood that an individual will consider the short and long-term consequences of his/her actions in pursuit of self-gratifying behavior-is a trait related to personal and violent victimization (Schreck, 1999). Unfortunately, research on these antecedents of violent victimization has often neglected how the two may be integrated to better understand violent victimization experiences among youth.

Commonly defined by high rates of poverty, residential turnover and ethnic heterogeneity, socially disorganized neighborhoods are contexts with structural and social characteristics that make personal vulnerabilities to crime heightened. For instance, researchers have observed that neighborhoods with more unemployment, poverty, and residential mobility will experience high rates of violent crime (Shaw \& McKay, 1942; Sampson, 2006). Such neighborhoods have limited means to informally control crime; sub-cultural values that may promote or encourage violence; residents who are less willing to trust one another; and a lack of cohesion and solidarity among residents (Kornhauser, 1978; Sampson, Raudenbush, \& Earls, 1997; Anderson, 1999). The structural and social disadvantages, combined with fear of retaliation in high crime areas, can make it less likely that residents will intervene for the common good of their community when disorder and criminal activity arise. Further, their lack of organization makes it more difficult to obtain outside resources that can reduce crime-related problems. Not only is crime more concentrated in such neighborhoods, research shows that children and adolescents growing up in these contexts are often more aggressive and more likely to engage in serious criminal activity (Leventhal \& Brooks-Gunn, 2000; Leventhal \& Brooks- 
Gunn, 2003). Impoverished neighborhoods that face such social challenges make it more likely that residents will encounter motivated offenders, which in turn can increase their risk of becoming a crime victim (Rountree et al., 1994; Sampson et al., 1997; Sampson \& Wooldredge, 1987).

Until recently, individual differences as explanations for understanding variation in criminal victimization have often taken a back seat to situational and contextual theories. Although early research did focus on demographic characteristics as indicators of criminal victimization vulnerability (see Von Henting, 1941), it was not until the last decade that an increase in studies focused on individual traits as risk factors for violent victimization (Schreck, 1999; Schreck et al., 2002; Higgins et al., 2010). One of the first studies to investigate low selfcontrol and personal victimization was conducted by Schreck (1999). He developed a theoretical argument as to why those who are deficient in self-control are more likely to be victims of crime. Since, several studies have replicated his findings using other samples and have extended them by showing that those possessing low selfcontrol are more likely to be repeat victims of crime (Higgins et al., 2010; Schreck, Stewart, \& Fisher, 2006).

Combining neighborhood-level and longitudinal data collected from youth in the Project on Human Development in Chicago Neighborhoods (PHDCN), the current study merges these two perspectives to illuminate how neighborhood context and individual differences in self-control predict violent victimization. Using multiple frameworks that hypothesize the dominance of social context and the interaction between neighborhood structure and individual differences, this 
study shows how self-control's influence on violent victimization is dependent on the structural aspects of neighborhoods in which children and adolescents live. Before discussing the results further, I briefly review studies that have investigated neighborhood influences on crime and criminal victimization. Second, self-control theory is reviewed as it relates to criminal victimization and studies that have found support for this link are summarized. Finally, I discuss the significance of the current study by merging these two perspectives to articulate reasons for why these correlates of criminal victimization may interact to explain violent victimization among adolescents.

\section{THEORETICAL ORIENTATION AND BACKGROUND}

\section{Neighborhood Context, Crime, and Criminal Victimization}

For decades research has shown that crime tends to be concentrated in disadvantaged urban areas. Neighborhoods with elevated rates of poverty, residential turnover, and ethnic heterogeneity have higher violent crime rates, and individuals living in them are at an increased vulnerability for becoming victims of violence (Rountree et al., 1994; Sampson et al., 1997; Sampson \& Wooldredge, 1987). Known for their landmark study on social organization, Shaw and McKay (1942) were among the first to observe such patterns in geographical areas of Chicago. They offered a theory to explain these patterns by stating that such structural conditions made it difficult for residents in disadvantaged neighborhoods to organize in a way that would combat or informally control criminal activity. 
Several scholars have extended Shaw and McKay's research by measuring intervening mechanisms that offer explanations for why residents in disorganized neighborhoods are less capable of controlling crime. Weak interpersonal and organizational networks, inadequate informal social control, sub-cultural and competition models that may encourage violence, and mistrust among neighbors have all been studied as mechanisms that are possibly important for explaining the connection between structural disadvantage and neighborhood crime rates (e.g., Anderson, 1999; Kornhauser, 1978; Sampson \& Groves, 1989; Warner \& Wilcox Rountree, 1997).

In their well-known study, Sampson and colleagues (1997) empirically extended social disorganization theory by identifying factors that can promote order and consequentially lead to less vulnerability to crime and violence in neighborhoods. They labeled this construct "collective efficacy." Collective efficacy is the willingness of neighborhoods residents to exercise informal social control in situations of disorderly conduct (e.g., kids loitering outside while truant, painting graffiti) and to intervene for the common good of their neighborhood, coupled with trust and cohesion among one another (see Sampson, 2006). As Morenoff and colleagues (2001) stated, while the networks responsible for collective efficacy are often weak in intensity, they should be sufficient for the promotion of order and informal social control of violence.

Sampson and colleagues (1997) were among the first to find that neighborhood collective efficacy is strongly related to violent crime. Using data from the Project on Human Development on Chicago Neighborhoods, they found 
that collective efficacy mediated neighborhood structural variables, on neighborhood violence. Research shows that collective efficacy can explain the correlation between neighborhood social disorder and crime (Sampson et al., 2001), and collective efficacy has been associated with antisocial and aggressive behavior among youth. Children living in neighborhoods with more collective efficacy are less likely to engage in violence (Berg \& Loeber, 2011; Maimon \& Browning, 2010; Sampson, Morenoff, \& Raudenbush, 2005). In sum, violence and other social ills tend to cluster and persist in neighborhoods where trust and cohesion is low among residents and informal social control is lacking. Furthermore, in such neighborhoods sub-cultural values that encourage violence are often present, and competition for respect can result in violence (Anderson, 1999).

Given that violent offending and victimization are strongly correlated (Berg \& Loeber, 2011; Hindelang et al., 1978; Lauritsen \& Laub, 2007; Lauritsen, Sampson, \& Laub, 1991), it comes as no surprise that neighborhood structural and social factors are also related to violent victimization risk (e.g., Berg \& Loeber, 2011; Lauritsen, 2001; Miethe \& McDowall, 1993; Sampson, 1985; Sampson \& Wooldredge, 1987). Independent of demographic characteristics, research shows that neighborhood poverty, residential mobility, and family structure increases the likelihood of violent victimization (Sampson, 1983; Sampson, 1985; Lauritsen, 2001).

More recent attempts have connected the social processes within neighborhoods to violent victimization risk (Velez, 2001). With a desire to explain community variation in criminal victimization, researchers have integrated the 
routine activity and lifestyles perspectives with social disorganization and collective efficacy (e.g., Lee, 2000; Wilcox, Land, \& Hunt, 2003). Clearly, community social control and collective efficacy intersect with the routine activity concept of guardianship. Marcus Felson (1998) noticed that the most effective guardianship is informal, where the presence of others deters criminal victimization. This is especially true since formal agents of social control (e.g., the police) infrequently appear in citizen's lives. Routine guardianship must therefore result from informal control. As Lee (2000:687) stated, guardianship exists within "the constellation of networks and social interactions with other individuals and groups external to the individual."

Using data from the Project on Human Development in Chicago Neighborhoods, the British Crime Survey (BCS), and the Seattle phone survey researchers have scrutinized the joint contribution of individual and neighborhoodlevel risk factors for criminal victimization. For instance, Sampson and Wooldredge (1987) used data from the BCS and found that while lifestyles of adults (e.g., living alone or frequent out-of-home activity) influenced violent victimization risk, aggregated neighborhood factors were also important. Specifically, contextual factors including family disruption, social cohesion, and the amount of activity on neighborhood streets all had significant associations with risk for being robbed. Other research in a variety of contexts shows similar results (e.g., Kennedy \& Forde, 1990; Fisher, Sloan, Cullen, \& Lu, 1998; Miethe \& McDowall, 1993; Thompson \& Fisher, 1996). For instance, Meithe and McDowall (1993) used data from the Seattle phone survey and found that people living in poorer and busier neighborhoods 
were at risk for being victims of stranger violence. In a re-analysis of the Seattle data, Wilcox-Rountree and her colleagues (1994) used a multi-level model that accounted for the fact that community residents are not randomly assigned to neighborhoods and, with few exceptions, found similar findings; that is, risk of victimization varied significantly across neighborhoods and was influenced by contextual variables including density, disorder, and ethnic heterogeneity. Sampson and colleagues (1997) found that risk for violence among residents was reduced in Chicago neighborhoods that possessed greater collective efficacy. Taken together, there is impressive consistency in the results that link community characteristics to criminal victimization, especially when one considers the variety of contexts examined.

Extant studies on the influence of neighborhood conditions on violent victimization share some noteworthy limitations. First, they have largely used adult samples (e.g., Lauristen, 2001), leaving several questions unanswered about how neighborhood conditions may influence violent victimization among adolescents. This is an important area of research because adolescents are at most risk for becoming victims of violence. Second, although past research has found relationships between neighborhood conditions and violent victimization, most of these studies have rarely moved beyond incorporating individual-level demographic factors and lifestyle characteristics that distinguish between individuals. This limitation makes it less clear as to whether other theoretically driven individual risk factors that are related to violence are important for understanding how neighborhood conditions influence violent victimization of 
adolescents. Given the general lack of attention to neighborhoods and violent victimization among adolescents, this initial study focuses on the intersection of neighborhood disadvantage and individual differences among adolescents to better understand their violent victimization experiences.

\section{Self-Control, Lifestyles, and Violent Victimization}

Gottfredson and Hirschi's General Theory (aka, self-control theory) is one of the most tested theories of crime, violence, and deviant behavior (Pratt \& Cullen, 2000). Their theory is premised on a trait—low self-control—that is allegedly formed in childhood due to inadequate parental socialization and disciplining practices. According to Gottfredson and Hisrchi (1990), once formed this trait remains relatively stable over the life-course. Those who possess lower self-control are likely to gravitate toward activities that bring short-term pleasures, but can have negative long-term and contemporaneous consequences. Gottfredson and Hirschi (1990) argue that decisions not to consider the long-term consequences of one's own behavior in the pursuit of self-gratifying acts is indicative of characteristics such as the inability to delay gratification, risk-taking and impulsivity, a lack of diligence in working toward goals, low tolerance for frustration, and a preference for physical rather than cognitive tasks. Gottfredson and Hirschi's theory was meant to reach further than simply explaining involvement in crime. Research has confirmed this by showing that children, adolescents, and adults lacking self-control are more at risk for a host of negative outcomes including involvement in violence, poor health, accidents, disease, poor educational attainment, unstable work histories and drug use to name a few. In fact, the interest in low self-control and its 
consequences for social and behavioral outcomes binds several academic disciplines ranging from neuroscientists who study it as a brain function (Elsinger, FlahertyCraig, \& Benton, 2004); geneticists and biosocial criminologists who show that it has hereditary underpinnings (Bouchard, 2004; Beaver, Wright, DeLisi, \& Vaughn, 2008); economists who believe that it can help with population financial conditions (Heckman, 2007); and psychologists focusing on ways to improve the development of self-control among children (Kochanska, Coy, \& Murray, 2001).

Schreck (1999) was one of the first to recognize that Gottfredson and Hirschi's self-control theory is also applicable to criminal victimization. In doing so, he observed that self-control theory is logically consistent with situational theories of victimization by showing how those with lower self-control make decisions about their lifestyles and have personal characteristics which make them highly vulnerable to crime (Schreck et al., 2002). For instance, because those with low selfcontrol are more aggressive and have aversive personal styles others are more likely to have grievances against them. Felson (1984) found that most physical assaults took place when aggrieved parties attacked the person who had injured them. This pattern appears often in the violence literature (e.g., Anderson, 1999; Jacobs \& Wright, 2006). With respect to property victimization, the tendency to lack foresight and to be habitually lazy works against efforts at self-protection, since selfprotection entails at least some inconvenience (Schreck, 1999). Characteristics such as impulsivity and risk-seeking can lead individuals into situations that put them in closer proximity to offenders and situations that generally come with a higher risk for being criminally victimized. 
Employing various samples and methods, recent research by Schreck and others (e.g., Higgins et al., 2010; Schreck, Stewart, \& Fisher, 2006; Stewart, Elifson, \& Sterk, 2004) shows that those who possess lower self-control are at increased risk for violent victimization. This research has shown that low self-control influences violent victimization independent of lifestyles and other risk factors such as peers, indicating that the presence of self-control can independently make a situation safer while low self-control can worsen personal safety and one's possessions in even an otherwise innocuous situation (Schreck et al., 2002; Stewart et al., 2004). Researchers also find that self-control has influences on trajectories of violent victimization (Higgins et al., 2010). At least one study indicates that low self-control individuals who are victims are unlikely to change their routines which may protective them from future victimizations (Schreck et al., 2006).

Some of the most recent research shows that when models are estimated simultaneously using bivariate probit models, those possessing low self-control are more likely to be both offenders and victims of crime (Jennings, Higgins, Tewksbury, Gover, \& Piquero, 2010); thus, further confirming Lauritsen and colleagues (1992) idea that theoretical constructs predictive of crime also predict victimization. Importantly, these recent studies bring together literature that has investigated the influence of low self-control on offending and victimization separately over the past twenty years. These findings, however, come as no surprise for a couple of reasons. First, a growing body of literature has shown that offending and victimization are both predicted by low self-control. Second, for decades criminologists have been aware of a connection between offenders and victims (e.g., Jensen \& Brownfield, 
1986; Lauritsen, Sampson, \& Laub, 1991; Luckenbill, 1977; Wolfgang, 1958);

offenders and victims share similar demographic profiles and self-report research shows that the frequency of involvement in crime is positively correlated with victimization. The offender/victim nexus is often attributed to either sub-cultural norms of retaliation (e.g., Berg \& Loeber, 2011; Jacobs \& Wright, 2006; Singer, 1981; Stewart et al., 2006) or lifestyles that embed offenders into social networks or contexts where individuals prey upon one another (Lauritsen et al., 1991; Schreck et al., 2004). Now research shows that low self-control is partially responsible for this overlap, but it cannot fully account for the correlation between victimization and offending behavior.

Although the criminological literature has established that low self-control is a risk factor for violent victimization, researchers have largely neglected the contexts in which low-self-control leads to a greater vulnerable to violence. One such context is the neighborhoods in which children and adolescents live. Reasons for why neighborhood conditions may help understand the relationship between low self-control and violent victimization risk are described below.

\section{The Current Study}

It has been established that neighborhood structural conditions and individual differences in low self-control can independently influence violent victimization risk. At present, the role of low self-control as a facilitator of violent victimization vis-à-vis imposed neighborhood factors is unknown. That is, does violent victimization risk depend on both or do they each have independent 
influences? The importance of the current study is then to understand how neighborhood differences and differences in low self-control jointly shape violent victimization risk.

Several perspectives have been advanced to explain how social context and traits will interact to shape individual outcomes. First, intended for understanding biosocial phenomena, Raine $(1988 ; 2000)$ proposed a "social push" perspective to make sense of the interplay between social environments and traits for understanding how biologically-related variables influence antisocial outcomes ${ }^{1}$. His notion of "social push" suggests that environments can be "weak" or "strong." Particularly important for the current study is the notion of a "strong" environment, which is a context that purportedly minimizes the influence of biological and trait based individual differences because of the strong pressures or "push" to behave in particular ways (Lynam, Caspi, Moffitt, Wikstrom, Loeber, \& Novak, 2000; Mischel, 1977). Disadvantaged neighborhoods represent a context identified by researchers as a strong environment. These are contexts where normative cultures are more likely to strongly influence the behavior of people, especially antisocial and violent behaviors. Anderson's (1999) qualitative work on the code of the streets in urban, impoverished neighborhoods exemplifies the idea of strong social environments. Youth residing in such neighborhoods must often adopt the "street code" to gain respect and to avoid future vulnerabilities to criminal violence. Raine argues that

\footnotetext{
${ }^{1}$ While Raine's "social push" perspective suggests that neighborhood social disorganization may be one of several social environments that can be important for understanding violence and conduct problems among children and adolescents, it should not be confused with social disorganization theory. Importantly, Raine suggests that an interaction will exist between social environments and biological/trait-based variables for understanding child outcomes. Social disorganization theory doesn't suggest such an interaction.
} 
individual differences among adolescents in such contexts may not matter much at all because of the social pressures that are present.

On the other hand, Raine suggests that in contexts where social pushes toward violence are weaker the influence of traits will have stronger influences on antisocial, aggressive, and violent behavior. These behaviors are to a lesser degree influenced by environmental social pressures. From a neighborhood perspective, and for the purpose of the current study, the least disadvantaged neighborhoods should have less social pressures for youth to engage in crime and violence, consequently leading to a reduced threat of violent victimization.

Second, Gottfredson and Hirschi's theory suggests that neighborhood factors are to a substantial degree determined by self-selection. For instance, those with low self-control would be unable to hold work that paid well and therefore would, absent of other sources of support, drift toward disadvantaged neighborhoods, possibly increasing the potential number of offenders in a particular. Those with low self-control might have friends, but their ties with others are likely of low quality (Gottfredson \& Hirschi, 1990). To them, neighborhood disorganization and vulnerability to crime in these areas would be largely a by-product of an excess of residents with low self-control. To the extent that neighborhood structure is plausibly determined by the aggregate characteristics of individual residents, any connection between neighborhood risk factors and violent victimization should be spurious.

Third, neighborhood contextual variables may moderate the relationship between low self-control and violent victimization. Structurally disadvantaged may 
increase individual vulnerability to violence due to a combination of greater amounts of violence in such neighborhoods, a higher concentration of offenders, and generally less informal social control and cohesion. Further, sub-cultural norms in disadvantaged neighborhoods may encourage violence as an acceptable means for handling grievances or confrontations with others (Anderson, 1999). Under these conditions individuals with low-self control may be especially vulnerable to violent victimization because they possess characteristics that make them difficult to reason with; they are impulsive; they often find themselves in more risky situations; and they may be less aware of their surroundings. The personal styles of low selfcontrol individuals, combined with living in neighborhoods where rates of violence are high and violence is often used as a means for dealing with confrontation, can make the threat of violence against them amplified. On the other hand, individuals possessing more self-control may have a lowered risk of becoming victims of violence in disadvantaged neighborhoods because they may have a heightened sensitivity to neighborhood dangers and try to make sure they avoid situations and people that would otherwise put them at elevated risk for violent victimization. They will consider the potential consequences of their actions more often than those with lower self-control; in this case it would be the real threat of becoming a victim of violence. Further, in view of the fact that those with high self-control will act in ways that are less likely to provoke others, as well as to be cognizant of the necessity of protective behaviors, then it would seem to follow that youth living in high risk environments will have a reduced risk for becoming victims of violence because they posses heightened sensitive to their environment. 


\section{Hypotheses}

Several competing hypotheses can be drawn from the perspectives discussed above and the literature on neighborhoods, self-control, and violent victimization.

1. Youth with lower self-control will have significantly higher risk of becoming victims of violence when statistically controlling for neighborhood context, lifestyles, and prior involvement in violence.

2. Youth residing in structurally disadvantaged neighborhoods will have significantly higher risk of becoming victims of violence when statistically controlling for self-control and other individual characteristics known to increase the risk for violent victimization.

3. From the "social push" perspective, low self-control will not significantly increase the risk of violent victimization among those residing in the most structurally disadvantaged neighborhoods, but low self-control will significantly influence violent victimization risk for youth residing in the least disadvantaged neighborhoods.

4. Youth with lower self-control will have significantly higher risk of becoming victims of violence in most disadvantaged neighborhoods; whereas those possessing more self-control will have significantly lower risk of becoming victims of violence in the most disadvantaged neighborhoods. 


\section{METHODS}

\section{The Project on Human Development in Chicago Neighborhoods}

Data from the 9,12, and 15 year-old cohorts from the Longitudinal Cohort Study in the Project on Human Development in Chicago Neighborhoods (PHDCNLCS) were analyzed to test the current study' hypotheses. Self-reported violent victimization measured at wave 2 is predicted using individual-level predictors from waves 1 and 2 of the longitudinal cohort study. Additionally, 1990 U.S. Census data were used to measure neighborhood-level structural variables of the 80 neighborhood clusters, i.e., aggregations of 1 to 3 Census tracts, in which these youth reside. Through combining data from the longitudinal cohort study and 1990 U.S. Census data specific to the neighborhoods in which these youth reside, the PHDCN is appropriate for assessing the influence and intersection between neighborhood structural disadvantage and individual-level factors on children and adolescents violent victimization. A wealth of neighborhood structural, organizational, and social process measures exist that have been validated over time ${ }^{2}$, making the PHDCN a unique study on neighborhoods (Raudenbush \& Sampson, 1999; Sampson et al., 1997).

The PHDCN was implemented in 1995 to collect reliable and valid data on the neighborhood contexts in which children and adolescents develop. The sampling design of the PHDCN contains two components: selection of neighborhood

\footnotetext{
${ }^{2}$ For a detailed explanation and discussion of the independent community survey design and the instrument used to collect data on the social processes occurring in the sampled NCs please see the following website http://www.icpsr.umich.edu/PHDCN.
} 
clusters and selection of children and their primary caregivers for the longitudinal study. The 865 Chicago census tracts were combined to create 343 homogenous neighborhood clusters (NCs), which were combined based on census tract similarities such as race, ethnicity, socioeconomic conditions, family structure, and other geographical boundaries such as railroad tracks and parks (Sampson et al., 1997). NCs averaged approximately 8,000 people each ${ }^{3}$. The 343 NCs were stratified by seven racial and ethnic categories and three categories of socioeconomic status, i.e., high, medium, and low. With the goals of achieving a balanced design and to minimize confounding between SES and race/ethnicity, a sample of 80 NCs was selected from within the strata of 343 NCs to be used for the PHDCN-LCS. The 80 sampled NCs were representative of the racial, ethnic, and socioeconomically diverse Chicago neighborhoods 4 (Molnar, Buka, Brennan, Holton, \& Earls, 2003; Sampson et al., 1997; Sampson, Morenoff, \& Earls, 1999).

Within the 80 NCs, approximately 6,500 children and adolescents, along with their primary caregivers, were randomly selected. Starting with a random selection of block groups within NCs, a list of dwellings was compiled and household members were enumerated. In total, approximately 40,000 dwellings were screened. Study recruitment consisted of infants, children, adolescents (including

\footnotetext{
${ }^{3} \mathrm{NC}$ 's are different from the traditional community areas of Chicago that have approximately 40,000 people each. NC's are composed of geographically contiguous census tracts that are relatively homogenous to one another.

${ }^{4}$ As part of the PHDCN design, diversity across neighborhoods was important. Sampled neighborhoods varied by race and ethnic composition as well as socioeconomic status. Strata were created using seven categories of racial/ethnic composition and 3 categories of socioeconomic status. This resulted in 21 strata where each NC fit into one of the strata. For instance, $77 \mathrm{NCs}$ are $75 \%$ Black and on average have low socioeconomic status, whereas, $11 \mathrm{NCs}$ were classified as being $75 \%$ Black and on average having high socioeconomic status. In addition, no NCs were $75 \%$ Hispanic and high socioeconomic status; likewise, no NCs are partially Hispanic and Black that are on high socioeconomic status.
} 
18 year olds) and their primary caregivers. For selection, subjects had to be within approximately six months of the following age categories: $0,3,6,9,12,15,18$ years. Extensive interviews were conducted with these children and their primary caregivers over three waves of data collection spaced approximately 2.5 years apart. The longitudinal study began in 1995; the second wave of data collection occurred between 1997 and 1999; and the third wave of data was collected between 2000 and $2001^{5}$. This effort resulted in seven cohorts that span a period of development between infancy and early adulthood6.

\section{Analysis Sample}

The analysis sample consists of 1,889 children and adolescents from the 9 (n =669), $12(n=674)$, and 15 year-old cohorts $(n=546)$ and their primary caregivers from waves 1 and 27,8. Table 1 reports several descriptive statistics for the analysis sample. The sample is 15\% White, $34 \%$ Black, $47 \%$ Hispanic, and 3.5\% other. Males

\footnotetext{
${ }^{5}$ Readers are refered to http://www.icpsr.umich.edu/icpsrweb/PHDCN/about.jsp for more information on when waves 1,2 , and 3 were collected.

${ }^{6}$ At wave 1 of data collection there were 1,269 subjects in cohort $0,1,003$ subjects in cohort 3,980 subjects in cohort 6,828 subjects in cohort 9, 820 subjects in cohort 12,696 subjects in cohort 15,632 subjects in cohort 18 .

${ }^{7}$ Due to attrition, the original sample of 2,345 subjects in cohorts 9,12 , and 15 was reduced to 1,889 . Ttest comparisons of demographic and individuals characteristics for those in the attrition group to those remaining in the sample at wave 2 revealed non-significant differences for age, gender, SES, and low selfcontrol; however, statistically significant differences were observed for delinquent peers, single parent family structure, and supervision. Youth not in the sample at wave 2 had more delinquent peers, more likely to be from single parent households, and their primary caregivers provided less supervision. Youth who were no longer in the study at wave 2 were excluded from the final analysis. To account for the relatively small amount of additional missing data, regression imputation was used to arrive at the analysis sample. Specifically, a single regression imputation was used for independent variables by regressing each variable with some missing data on variables such as age, gender, race, parenting variables, self-control, etc. Regression imputation was used for all covariates (with the exception of demographic variables) to predict violent victimization at wave 2 . To be clear, multiple imputation techniques were not used for the final analysis.

${ }^{8}$ The decision to use data from subjects in the 9,12 , and 15 -year old cohorts was based on the following criteria. First, these age groups are at a heightened risk for violent victimization, especially 2.5 years later at wave 2 when the dependent variable was measured. Second, this study uses data collected from waves 1 and 2 where violent victimization is the outcome at wave 2 and individual variables measured at wave 1 are covariates (with the exception of unstructured time spent with peers which was measured at wave 2 and not measured at wave1).
} 
make up $50 \%$ of the sample and the average age at wave 1 is approximately 12 years old, which ranges from 7 to 16 years of age. Approximately $23 \%$ of the children were from single-parent households. These children and their families resided within 79 of the 80 neighborhood clusters that were randomly selected for the longitudinal cohort study.

\section{Measures}

Dependent Variable

Violent Victimization. A measure of violent victimization was created using responses to seven questions from the Exposure to Violence (ETV) interview administered to subjects during wave 2 interviews. Subjects were asked whether in the past 12 months have they been: hit, slapped or beaten up, attacked with a weapon, shot, shot at, sexually assaulted, and if someone has threatened to seriously hurt them. Given that approximately $70 \%(n=1,333)$ of the analysis sample reported not being a victim of any of the seven types of violent victimizations and that very few experienced two or more of these ${ }^{9}$, a decision was made to use a prevalence measure indicating whether or not they reported being violently victimized in the past 12 months. To this end, $29.4 \%(n=556)$ of the children and adolescents in the analysis sample reported being a victim of one or more of the

\footnotetext{
${ }^{9}$ In the 12 months prior to wave 2 interviews, $18.5 \%(\mathrm{n}=351)$ reported experiencing one type of victimizations, $6.99 \%(\mathrm{n}=132)$ reported experiencing two types of victimizations, $2.38 \%(\mathrm{n}=45)$ reported experiencing three types of victimizations, $.95 \%(\mathrm{n}=18)$ experienced four types of victimizations, and $.53 \%$ experienced five types of victimization. No subject in the analysis sample reported being a victim of six or seven types of violent victimizations.
} 
seven types of violent victimization during the 12 months prior to wave 2

interviews ${ }^{10}$.

Individual-Level Independent Variables

Low Self-Control. Following past research (Gibson et al., 2009; Gibson,

Sullivan, Jones, \& Piquero, 2010), a seventeen-item measure of behavioral indicators

of low self-control was constructed using the Emotionality, Activity, Sociability, and

Impulsivity (EASI) temperament survey. Administered during wave 1 interviews,

primary caregivers were asked to report on their child's inhibitory control, decision

making, risk and sensation seeking, and diligence or persistence in completing tasks

(see also Buss \& Plomin, 1975; see Appendix B for individual items), which are

consistent with Gottfredson and Hirschi's (1990) definition of self-control, as well as

past empirical research (see Grasmick, Tittle, Bursik, \& Arneklev, 1993) ${ }^{11}$.

Inhibitory control indicates the inability to delay gratification and control

frustrations, such as trouble controlling impulses and having problems with

resisting temptations. Items measuring decision time represent the (in) ability to

delay decision making until alternatives can be seriously considered including

10 To provide a better understanding of the type and context of violent victimization, Table 2 shows selfreported counts of victimizations by where they occurred and what the actual victimization type was for those reporting victimization at wave 2 . The types of context that could be reported for each type of victimization were limited to occurrences in one's own home, in someone else's home, at school, in their neighborhood, or outside the neighborhood. Several patterns emerged. First, the most common context for violent victimization was the neighborhoods in which these adolescents live. Other common contexts were the school and outside of the neighborhoods. Less common contexts were the respondents' own homes and home that are not theirs. Of the types of violent victimizations, the most commonly reported by victims were being chased; hit, slapped, punched, or beaten up; and threatened to seriously hurt. The other four types of violent victimization were less common among respondents, i.e., being shot, shot at, sexually assaulted, and attacked with a weapon. For instance, only four respondents reported being shot, with three occurring in the neighborhood and one occurring outside of the neighborhood.

${ }^{11}$ Self-control has been measured in past studies using a variety of behavioral and attitudinal items (Pratt \& Cullen, 2000). With some exceptions (Ward, Gibson, Boman, \& Liete, 2010), researchers have found that behavioral and attitudinal measures of self-control perform similarly and that there is little evidence that one is more highly valued than the other (see Tittle, Ward, \& Grasmick, 2003). 
saying the first thing that comes into one's head, trouble making up mind, and acting on the spur of the moment. Taken together, inhibitory control and decision time represent what Gottfredson and Hirschi (1990) refer to as impulsivity, a main component of low self-control. Sensation seeking, or what Gottfredson and Hirschi (1990) refer to as risk seeking, reflects a preference for novel stimuli, such as seeking new and exciting experiences, doing "crazy" things, and willingness to try anything. Persistence, or diligence as Gottfredson and Hirschi (1990) call it, is the likelihood that a child will complete or follow through with tasks they start. Children with low self-control are often the first to initiate a task, but also the first to abort them, especially when it doesn't involve immediate gratification.

For each subject, item responses were summed and standardized $(\alpha=.68)$. More positive scores indicate lower self-control; whereas more negative scores indicate higher self-control. Other studies using the PHDCN have used this same measure (also see Gibson et al., 2010; Gibson et al., 2009).

Family Attachment and Support. Family attachment and support has been repeatedly shown to be a predictor of violence and victimization, and it has also been related to children and adolescents' self-control development (Gottfredson \& Hirschi, 1990). Following Maimon and Browning (2010), a family attachment and support measure was constructed using six-items from the Provision of Social Relations instrument administered during the wave 1 interviews to subjects $(\alpha=$ .60 ). This measure gauges the level of perceived emotional and social support provided by their families. On a scale ranging from not true (1) to very true (3), respondents were asked to respond to the following statements regarding their 
family: "I know my family will always be there for me", "my family tells me they think I am valuable", "my family has confidence in me", "my family helps me find solutions to problems", "I know my family will always stand by me", and "sometime I am not sure I can rely on family" (reverse coded). The measure was standardized with higher scores indicating more family attachment and support.

Parenting. Parenting has been implicated in the development of self-control, as a social control mechanism for decreasing the likelihood of misbehavior, and has been associated with adolescent victimization. Parenting measures were taken from the Home Observation for Measurement of the Environment (HOME) Inventory (Caldwell \& Bradley, 1984), and several scales within the HOME have been validated in past studies (Leventhal, Selner, O'Hagan, Brooks-Gunn, Bingenheimer, \& Earls, 2004). This inventory is generally designed to measure the quantity and quality of stimulation in a child's home environment from primary caregivers.

Parental sensitivity and responsiveness is one domain of parenting measured by the HOME, which consists of parental warmth and parental lack of hostility. Derived from observations of primary caregivers and children during the in-home interviews at wave 1 , the parental warmth measure consists of nine-items. Likewise, parental lack of hostility consists of several observations that interviewers recorded during the in-home interviews. Indicating a primary caregiver's knowledge of their child's whereabouts, familiarity with their child's friends, and rules surrounding curfews and activities with friends, the parental supervision measure is a thirteenitem scale of how primary caregivers directly and indirectly monitor and supervise 
their children. Each measure was standardized, and more positive scores indicate more supervision, more warmth and less hostility.

Lifestyle, Situational, and Behavioral Variables. Similar to prior research (Maimon \& Browning, 2010; Osgood \& Haynie, 2005) peer delinquency is measured using eleven -items from the Deviance of Peers instrument administered at wave 1 to children and adolescents to obtain information regarding the portion of their peers engaging in a variety of delinquent behaviors (see appendix B for individual items). For example, respondents were asked "during the past year, how many of the people you spend time with" have "stolen something worth more than $\$ 5$ but less than $\$ 500$ ", "gone into or tried to do into a building to steal something", "hit someone with the idea of hurting them", and "attacked someone with a weapon with the idea of seriously hurting them". Responses to questions ranged from 1 (none of them) to 3 (all of them). The measure was standardized $(\alpha=.81)$, and higher scores indicate having a larger amount of delinquent peers.

Prior violent offending behavior is included as a control because of the robust relationship between offending and victimization and the evidence showing that low self-control is related to both violent offending and victimization. During the first wave of data collection, children and adolescents were asked to self-report their involvement in a variety of criminal and serious delinquent acts. Seven questions that asked about violence were used to create a dichotomous measure indicating whether a respondent ever engaged in at least one violent offense. For instance, violent offending items include items such as "have you ever:" "attacked someone with a weapon", "used a weapon or force to get money or things from 
people", "been involved in a gang fight in which someone was hurt of threatened with harm", and "thrown objects, such as rock or bottles, at people." Youth reporting at least one violent offense were coded as 1 and those who reported none of the violent offenses were coded 0 . Of the analysis sample, 33 percent $(n=623)$ reported engaging in at least one of the violent offenses.

Following Osgood and colleagues (1996) and Maimon and Browning (2010), a measure of unstructured socializing with peers was constructed using a four-item scale of responses to questions that asked children and adolescents during wave 2: "how often do you ride around in a car/motorcycle for fun", "how often do you hang out with friends", "how often do you go to parties", and "how many days a week do you go out after school/at night." Responses to questions ranged from 1 (never) to 5 (almost everyday). The measure was standardized with higher scores indicating more time spent in unstructured activities with peers $(\alpha=.58)$.

Demographic Characteristics. Socioeconomic status is measured using the principal component of three variables including household income, maximum education level of primary caregiver and partner, and the socioeconomic index (SEI) for primary caregivers and partners jobs ${ }^{12}$. Gender of the subject was coded 0 (female) or 1 (male). Age of subject at wave 1 was measured as a continuous variable.

\footnotetext{
${ }^{12}$ See http://www.icpsr.umich.edu/PHDCN/imputations.htmlhttp://www.icpsr.umich.edu/PHDCN/imputations.ht $\underline{\mathrm{ml}}$ for a detailed explanation of the computation and imputation of this index.
}

This document is a research report submitted to the U.S. Department of Justice. This report has not been published by the Department. Opinions or points of view expressed are those of the author(s) and do not necessarily reflect the official position or policies of the U.S. Department of Justice. 


\section{Neighborhood-Level Variables}

Concentrated Disadvantage. A neighborhood structural disadvantage variable—or neighborhood poverty and segregation—is measured using a composite measure of several structural characteristics within each $\mathrm{NC}$ of the PHDCN-LCS. Originally created by Sampson and colleagues (1997) and shown to be a reliable construct, this measure is composed of six items taken from the 1990 U.S. Decennial Census and included the following variables: percentage neighborhood residents below the poverty line, percentage on public assistance, percentage of female-headed families, percentage unemployed, density of children by percentage younger than 18, and percentage Black. Higher scores on this measure indicate more neighborhood concentrated disadvantage. Additionally, neighborhood residential mobility was also included as a two-item measure that is commonly used in social disorganization research (Sampson et al., 1997). Higher scores indicate more residential turnover.

Violent Crime. This measure encompasses neighborhood violent crimes taken from incident-based records of the Chicago Police Department in 1993, which is a standardized measure of murders, robberies, rapes, and aggravated assaults. Higher scores on this measure indicate more violence in a neighborhood.

Neighborhood Social Process. Three neighborhood social process variables were considered for analysis. Taken together they represent child-based collective efficacy (Gibson et al., 2010; Sampson et al., 1999). These measures include intergenerational closure, reciprocal exchange, and child-centered social-control. While Sampson et al. (1999) argue that these social processes occurring in 
neighborhoods will affect the lives and development of children (see Appendix B for individual items $)^{13}$, it is argued in the current study that these measures are consistent with the concepts of guardianship or neighborhood-level social control directed at youth.

According to Sampson et al. (1999), intergenerational closure, measured using a five-item scale, assesses the closeness of parents and children within a community, and it is argued that this closeness is important for neighborhood control of children beyond parental childrearing practices and monitoring by providing social support for children, information to parents, and help in facilitating control. Items are coded on a five-point, Likert-type scale ranging from strongly disagree to strongly agree. Reciprocal exchange is measured using a 5-item scale that assesses the interaction of families with respect to childrearing (both parent and children). These exchanges can range from giving advice, material goods, and information on childrearing. Items are coded on a four-point scale and responses ranged from never, rarely, sometimes, or often. Child-centered social control relates to the collective willingness of neighborhood residents to intervene on behalf of children beyond intervention by a child's parent(s) (Sampson et al., 1999). Furthermore, this measure represents a neighborhood's willingness to take action to help monitor and look after children. On a five-point scale, residents were asked how likely (very unlikely to very likely) that their neighbors would do something if

\footnotetext{
${ }^{13}$ Neighborhood social processes are measured using data collected from the 1995 community survey of the PHDCN that was administered to approximately 8,782 study participants representing all of the 343 NCs. The goal was to generate a representative sample of households within each NC. In contrast to the US Census data, the survey data were collected to obtain a better understanding of Chicago neighborhoods as defined by residents themselves. Valid and reliable scales have been created using these data by aggregating individual residents' responses to the NC level (see Raudenbush \& Sampson, 1999; Sampson et al., 1999).
} 
youth were engaging in variety of inappropriate behaviors. For all three measures, scale scores are aggregated to the neighborhood-level and higher scores on each measure reflect more child-based collective efficacy or a greater degree of guardianship for youth in a neighborhood.

\section{Analytic Strategy}

The analysis proceeds using several steps for testing hypotheses regarding neighborhood structure, low self-control, and violent victimization. First, bivariate comparisons are made between violence victims and non-victims to determine the demographic and theoretically derived characteristics that distinguish the two groups. This is followed by an analysis in which self-reported violent victimizations are decomposed by context and type. Second, a series of logistic regression models are estimated to determine the independent influences of neighborhood variables and low self-control on violent victimization. Third, additional multivariate logistic regression models are estimated to determine if the influence of low self-control on violent victimization varies as a function neighborhood structural disadvantage. Finally, conditional predicted probabilities are graphed to allow for a better visualization of violent victimization risk across statistically important independent variables. 


\section{RESULTS}

\section{Differences Between Victims of Violence and Non-Victims}

Table 1 shows comparisons between subjects who self-reported at least one violent victimization to those not reporting a violent victimization 12 months prior to wave 2 on demographic characteristics, family/parenting variables, behavioral and lifestyle variables, and low self-control. First, a significantly large percentage of males reported being victims of violence compared to females; of those who were victims $57 \%$ were males and of those who were not victims $47 \%$ were male. On average, victims of violence were significantly older than non-victims; victims of violence had a mean age of 12.55 at wave 1 whereas the average age of non-victims was 11.705. Respondents who were victims of violence were also more likely to be from single parent household where the primary caregiver is typically the biological mother, $29.5 \%$ of victims of violence compared to $20.2 \%$ of non-victims. Black and Hispanic youth were significantly more likely to be victims of violence, but Whites were no more likely to be a victim than any others. Second, child and adolescent victims of violence had significantly more family support and warmth from their primary caregivers compared to non-victims, yet no significant differences between victims of violence and non-victims were observed for supervision and hostility from primary caregivers. Third, several significant differences were found between victims of violence and non-victims for lifestyle, situational, and behavioral characteristics. Victims of violence were significantly more likely to report engaging in violent offending at wave $1 ; 33 \%$ reported engaging in at least one of the violent offenses in their life time. Victims of violence also reported having significantly 
more delinquent peers and spending more time in unstructured activities with peers. Fourth, victims of violence, on average, had significantly lower self-control compared to non-victims; victims, on average, were .217 standard deviational units greater than the mean, whereas non-victims, on average, were .097 standard

deviation units below the mean. Finally, victims of violence were not significantly more likely to live in disadvantaged neighborhoods compare to non-victims. been published by the Department. Opinions or points of view expressed are those of the author(s) and do not necessarily reflect the official position or policies of the U.S. Department of Justice. 
However, this relationship was approaching statistical significance $(p=.056)$ and

was in the anticipated direction ${ }^{14}$.

\section{Type and Context of Violent Victimization}

To provide a more thorough picture of violent victimization for the analysis

sample, Table 2 shows self-reported counts of violent victimizations by where they

occurred and what the actual violent victimization type was for those reporting

violent victimization at wave 2 . The contexts that could be reported for each type of

violent victimization were limited to occurrences in one's own home, in someone

else's home, at school, in their neighborhood, or outside the neighborhood.

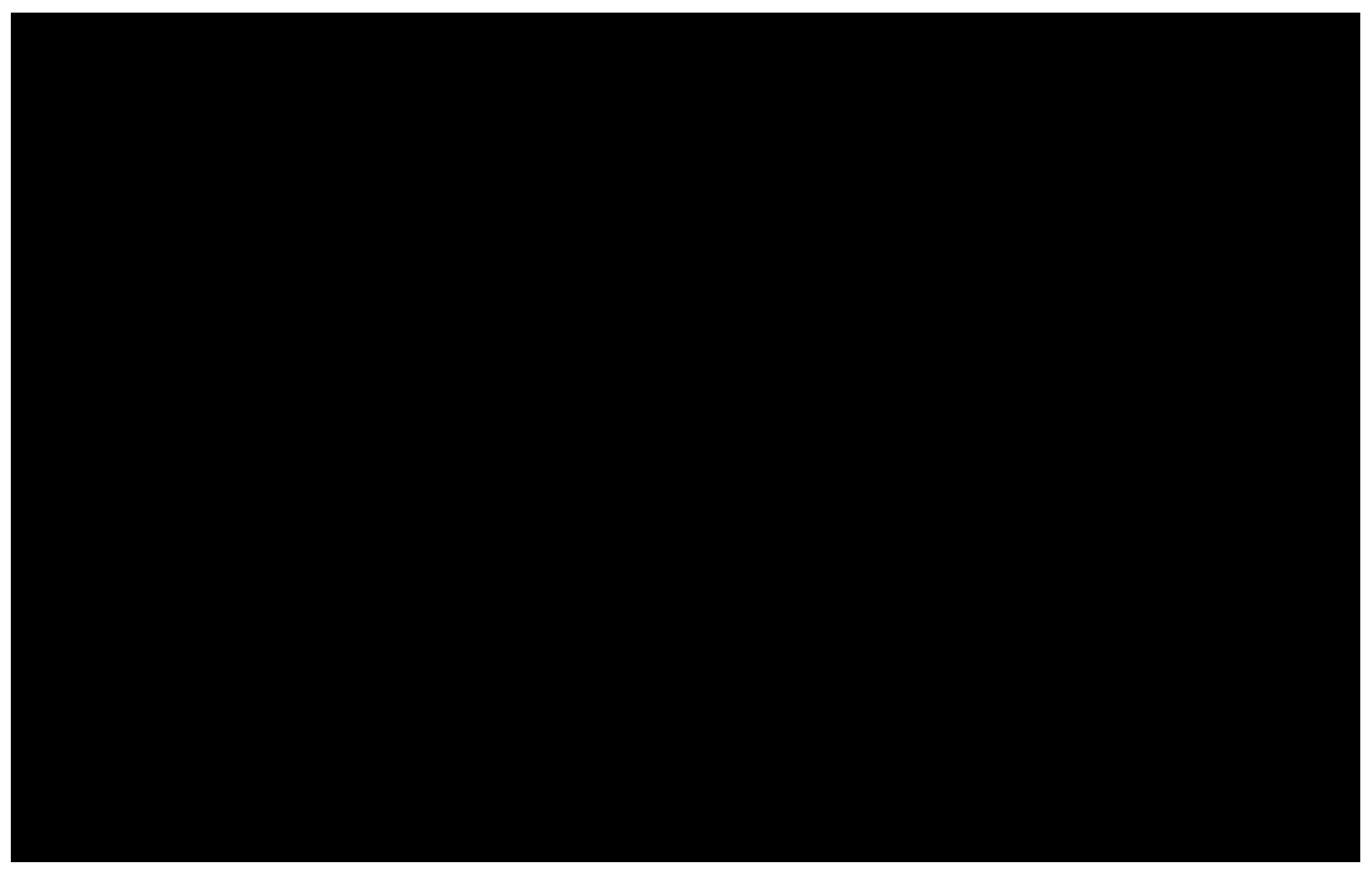

${ }^{14}$ An analysis that assessed bivariate differences for all independent and dependent variables across neighborhood type (i.e., low, moderate, and high concentrated disadvantage) was also conducted. In sum, the analysis showed several notable differences. Children and adolescents living in the most disadvantaged neighborhoods were, on average, the most likely to report violent offending, have the lowest levels of selfcontrol, and more likely to hang out with delinquent peers. Youth residing in the most disadvantaged neighborhoods, however, were supervised more closely compared to youth living in the least disadvantaged neighborhoods. 
Several patterns emerged. First, the most common context for the occurrence of violent victimization was either in school, own neighborhood, or outside of the neighborhood. Of these, the neighborhood was the most common context where violent victimization occurred. Some else's home was the least common context to experience a violent victimization. Of the types of violent victimizations, the most commonly reported by victims were being chased; hit, slapped, punched, or beaten up; and threatened to seriously hurt. The other four types of violent victimization were less common among respondents, i.e., being shot, shot at, sexually assaulted, and attacked with a weapon. For instance, only four respondents reported being shot, with three occurring in the neighborhood and one occurring outside of the neighborhood.

\section{Multivariate Analysis Predicting Self-Reported Violent Victimization}

To first address the hypothesis that violent victimization varies across neighborhoods and that it is more likely to happen to youth living in more structurally disadvantaged neighborhoods, a hierarchical generalized linear model (HGLM) was estimated. Results from this model indicated that violent victimization did not significantly vary across neighborhoods; therefore, a multilevel modeling approach to investigating the direct influences of neighborhood structural and social variables such as child-based collective efficacy and violence crime in 
neighborhoods on violent victimization was terminated at this point ${ }^{15}$. This result

also confirms the bivariate analysis reported earlier indicating that violent

victimization did not significantly vary by high, medium, or low neighborhood

structural disadvantage. To investigate the intersection between neighborhoods,

low self-control and violent victimization that is discussed later in this report, the

relationship between low self-control and violent victimization was estimated for

low, medium, and high concentrated disadvantaged neighborhoods ${ }^{16}$.

Table 3 shows four logistic regression models predicting wave 2 violent

victimization for those self-reporting at least one violent victimization in the

previous 12 months ${ }^{17}$. Model 1 includes only demographic characteristics and

consistent with past research shows that sex, age, race, and single parent family

structure significantly predict violent victimization. Males were significantly more

likely to report being a victim of violence compared to females $(\mathrm{OR}=1.584 ; \mathrm{p}<.05)$.

Older youth $(\mathrm{OR}=1.162 ; \mathrm{p}<.05)$ and youth living with only one parent were

significantly more likely to report being a victim of violence $(\mathrm{OR}=1.560 ; \mathrm{p}<.05)$.

Black youth were significantly more likely to report being a victim of violence

\footnotetext{
15 The unconditional model used to assess whether self-reported violent victimization at wave 2 significantly varied across neighborhoods was estimated using the xtmelogit command in STATA 11. The same model was also pursued using the HLM software, but convergence of the model could not be reached. In the original proposal it was argued that child-based collective efficacy and neighborhood violent crime would influence children and adolescents violent victimization. However, since statistically significant variation in violent victimization at wave 2 was not discovered these propositions could not be formally tested with the measure of violent victimization used in this study.

${ }^{16}$ An investigation of how neighborhood variables influence the relationship between low self-control and violent victimization was originally proposed to be conducted using hierarchical linear/generalized linear modeling. This was explored and the slopes of low self-control on violent victimization did not significantly vary across neighborhoods.

${ }^{17}$ Fixed effects were also estimated with HGLMs using the xtmelogit command in STATA 11. The results were similar for individual-level influences on violent victimization risk; therefore, a decision was made to report multivariate logistic regression models with robust standard errors to account for the fact that youth were nested within neighborhoods.
} 
compared to Whites (OR $=1.516)$, but Hispanic youth were no more likely than White youth to report being victims of violence.

Model 2 in Table 3 includes family and parenting variables. Family attachment had a statistically significant association with violent victimization $(\mathrm{OR}=$ $.875 ; \mathrm{p}<.05)$; youth reporting less attachment and support from their families were 
more likely to report being victims of violence. However, primary caregiver warmth, supervision, and hostility were not significantly associated with violent victimization. Sex, age, single parent family structure, and race (Blacks compared to Whites) retained statistically significant associations with violent victimization.

Model 3 in Table 3 assesses low self-control's influence on violent victimization when statistically controlling for demographic, family, and parenting characteristics. Importantly, low self-control had a positive and statistically significant association with violent victimization ( $O R=1.345 ; \mathrm{p}<.05)$; youth possessing lower self-control were more likely to report being victims of violence. While demographic variables retained their significant associations with violent victimization, family attachment and support became non-significant once low selfcontrol was statistically controlled.

Model 4 in Table 3 shows a full model that includes demographic characteristics, family and parenting variables, low self-control, and behavioral and lifestyle characteristics. Delinquent peers, self-reported violent offending, and unstructured time spent with peers each had independent statistically significant associations with violent victimization. Youth who reported a larger portion of their friends that engage in delinquent activities were more likely to report being victims of violence $(\mathrm{OR}=1.196 ; \mathrm{p}<.05)$. Youth reporting that they have committed at least one violent offense in their lifetime at wave 1 were also more likely to have reported a violent victimization compared to their non-violent counterparts. Unstructured time spent with peers also had a statistically significant association with violent victimization $(\mathrm{OR}=1.117 ; \mathrm{p}<.05)$; youth who spend more time in unstructured 
activities with peers were more likely to report being victims of violence.

Importantly, after statistically controlling for behavioral and lifestyle measures that are commonly known to have moderate to strong influences on violent victimization, youth with lower self-control were still significantly more likely to report being victims of violence compared to those youth with more self-control (OR $=1.287 ; \mathrm{p}<.05$ ). While sex, age, and single parent family structure retained their statistically significant associations with violent victimization; the difference in violent victimization between Blacks and Whites was accounted for by behavioral and lifestyle characteristics. Blacks were no more likely to be victimized than Whites after statistically controlling for peers, violent offending, and unstructured time spent in activities.

\section{Neighborhood Disadvantage, Low Self-Control, and Violent Victimization}

Table 4 shows logistics regression models testing the association between low self-control and violent victimization for youth residing in neighborhoods that are characterized by different levels of concentrated disadvantage ${ }^{18}$. The measure of neighborhood concentrated disadvantage had moderate to strong correlations with measures of neighborhood social processes and violence. Particularly noteworthy are the correlations between concentrated disadvantage, violent crime,

\footnotetext{
${ }^{18}$ Ideally, cross-level interactions using a random coefficients HGLM would be the most appropriate method to assess how the slopes of low self-control on violent victimization risk change across neighborhoods as a function of increases or decreases in neighborhood disadvantage. Due to the limited number of those who reported victimizations within neighborhoods it was determined to be inappropriate, thus making this a limitation of the present study. Nonetheless, in an attempt to investigate this relationship, I categorized neighborhood disadvantage into low, medium, and high. Acknowledging that within these neighborhood categorizations children and adolescents are still nested within a variety of NCs, I estimated robust standard errors that were used to adjust for the potential consequences associated with the lack of independence of residuals.
} 
and child-based social control. The most disadvantaged neighborhoods, on average, have the most violent crime $(.660 ; \mathrm{p}<.05)$ and the lowest amount of social control for children $\quad(-.479 ; \mathrm{p}<.05)$. Neighborhoods were classified as having low, medium, or high concentrated disadvantage by defining those at the lowest 25th percentile and lower as low disadvantaged; highest $25^{\text {th }}$ percentile and higher as the most disadvantaged; and those in between $25^{\text {th }}$ and $75^{\text {th }}$ percentiles as medium disadvantaged. As described below, the pattern of findings that emerged regarding the relationship between low self-control and violent victimization across level of disadvantaged neighborhoods is telling.

First, a logistic regression model for youth living in the lowest disadvantaged neighborhoods shows that the association between low self-control and violent victimization was statistically significant and positive. Consistent with the full model reported above, youth with lower self-control were significantly more likely to report being victims of violence. Additionally, delinquent peers, violent offending and unstructured time with peers had statistically significant associations with violent victimization. Youth in the lowest disadvantaged neighborhoods with more delinquent peers; those reporting past involvement in violent offending; and those spending more time in unstructured activities with peers were significantly more likely to report being victims of violence. Males and Blacks were also more likely to report being victims of violence in the lowest disadvantaged neighborhoods. Unlike in the analysis of the full analysis sample, statistically significant differences in violent victimization between Blacks and Whites persisted after controlling for violent offending, delinquent peers, and unstructured time spent with peers. 


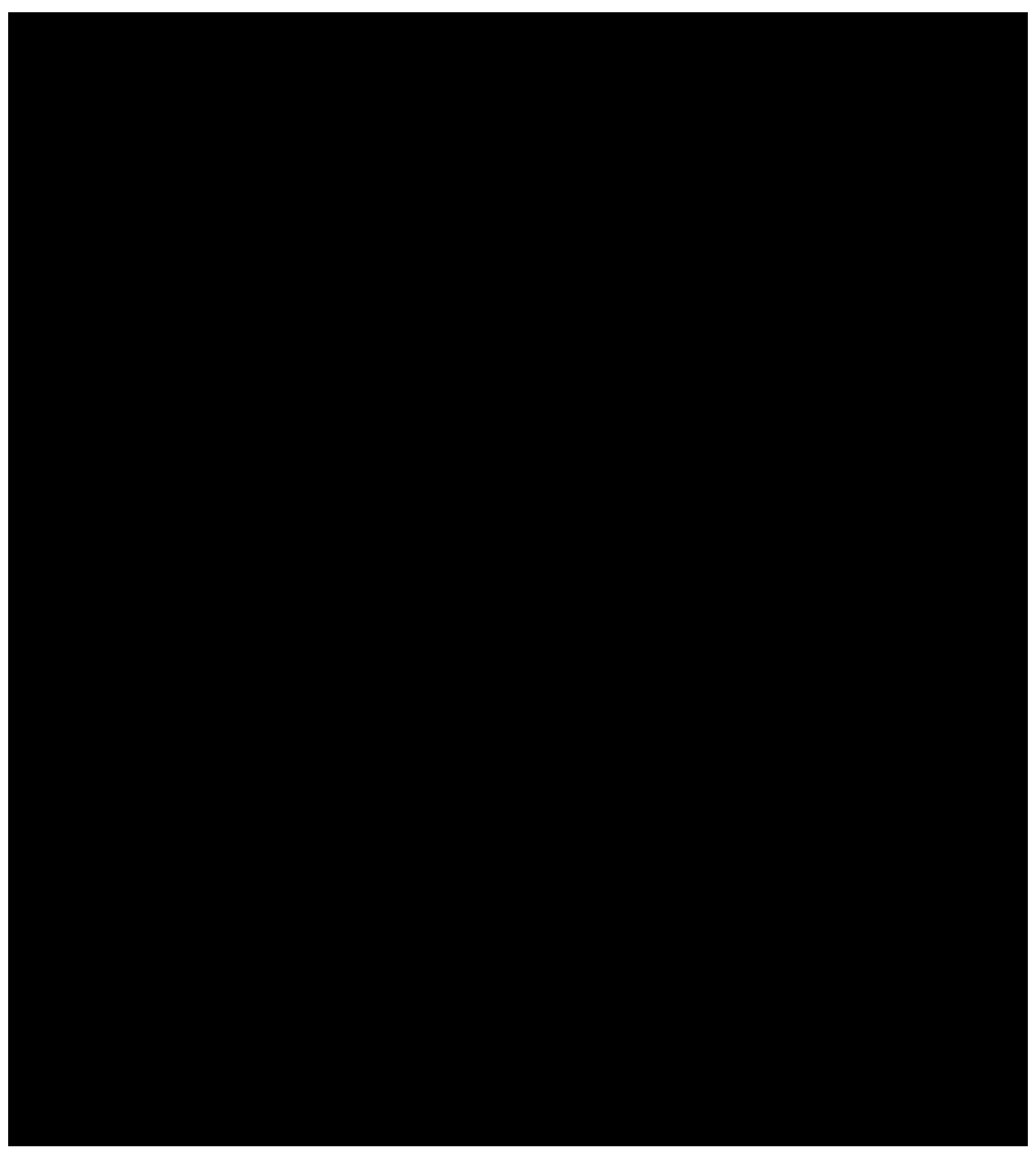

Second, Table 4 also shows results predicting violent victimization for those youth residing in medium or moderate structurally disadvantaged neighborhoods. Results are largely consistent with those from the low neighborhood disadvantage analysis. That is, low self-control continued to have a statistically significant and positive association with violent victimization. Moreover, youth residing in 
moderately disadvantaged neighborhoods were at heightened risk for violent victimization if they had more delinquent peers, engage in violent offending, and spend more time in unstructured activities with peers.

Finally, Table 4 shows strikingly different results for predictors of violent victimization among youth living in the most structurally disadvantaged neighborhoods. Unlike low and moderate disadvantaged neighborhoods, low selfcontrol did not have a statistically significant association with violent victimization in the most disadvantaged neighborhoods. Youth residing in high disadvantaged neighborhoods with lower self-control were no more likely than those with more self-control to report being victims of violence during wave two interviews. In addition, delinquent peers and violent offending—factors that past research has consistently found to be correlates of violent victimization—were not significantly associated with violent victimization. Unstructured time spent with peers is the only lifestyle characteristics that significantly increased the likelihood of violent victimization in highly disadvantaged neighborhoods.

\section{Conditional Probabilities of Violent Victimization from the Full Model}

This section reports conditional predicted probabilities for violent victimization at wave 2 . Conditional probabilities were estimated for variables that exhibited statistically significant associations with violent victimization in the full model in Table 3, which included sex, single parent family structure, low selfcontrol, and each of the behavioral and lifestyle variables. The conditional probabilities of violent victimization were calculated while statistically controlling for all other variables. 
First, males have a 30 percent chance of being a victim of violence while females' have a 25 percent chance. Youth from single parent households have a 34 percent chance of being a victim of violence.

Second, while statistically controlling for all covariates, Figure 1 shows that youth with lower self-control had a greater probability of being victimized by violence than those who had more self-control. Specifically, the x-axis shows a range of standardized values for the low self-control measure such that 0 is the average self-control for the analysis sample and negative and positive values represent standard deviations above and below the mean. Values above the mean indicate lower self-control and those below represent more self-control.

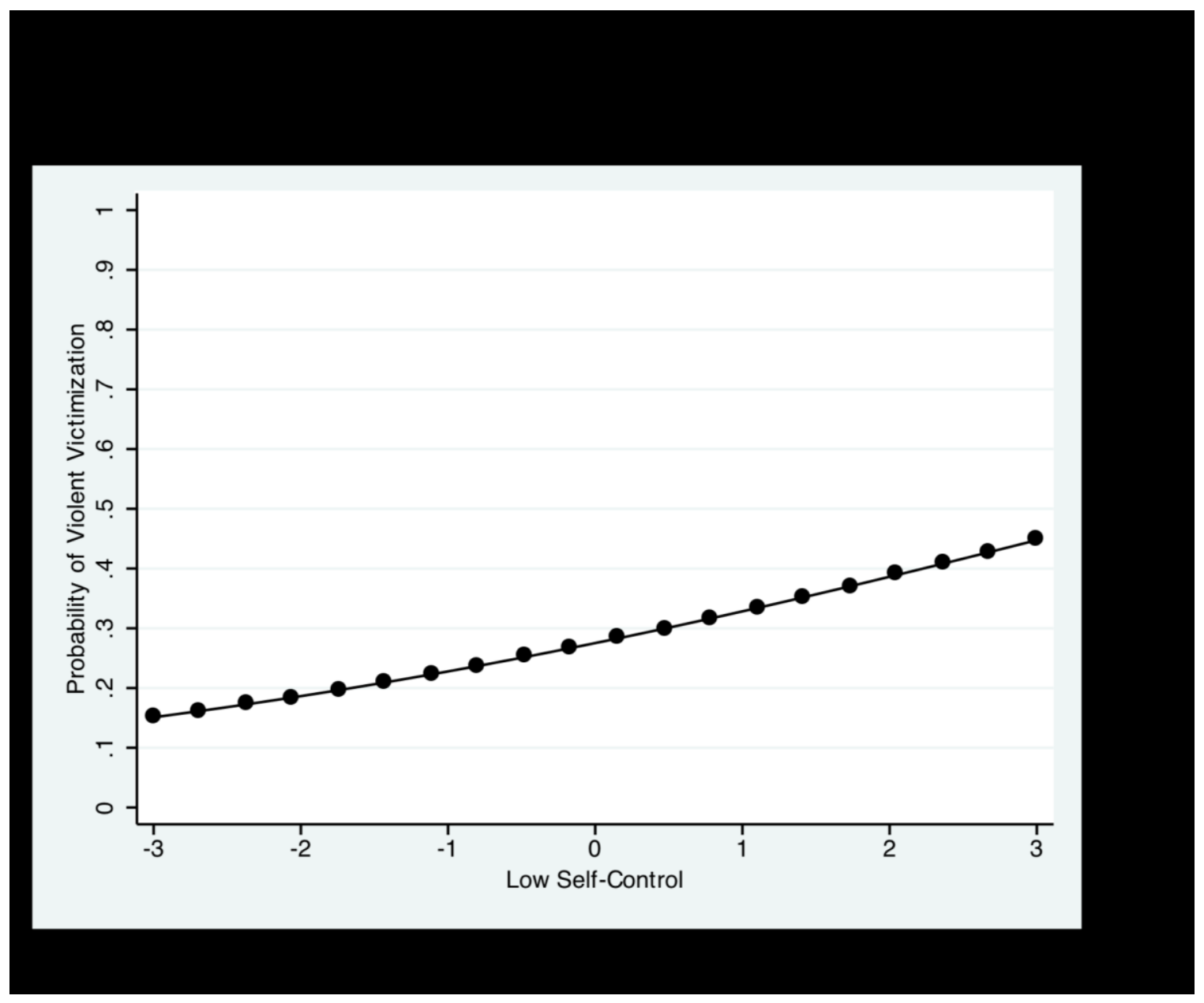

This document is a research report submitted to the U.S. Department of Justice. This report has not been published by the Department. Opinions or points of view expressed are those of the author(s) and do not necessarily reflect the official position or policies of the U.S. Department of Justice. 
The probability of violent victimization increases as a function of self-control scores, with larger probabilities related to scores above the mean and smaller probabilities related to self-control scores below the mean. For instance, youth scoring a -3 on the self-control measure, i.e., possessing the most self-control, have approximately a 15 percent chance of being victimized by violence at wave 2 . Youth with an average score on the self-control measure, i.e., 0 , have approximately a 25 percent chance of being victimized by violence. Youth scoring a 3, i.e., possessing the lowest selfcontrol, have approximately a 45 percent chance of being a victim of violence.

Third, while holding all other variables constant, Figure 2 shows that youth with more delinquent peers had a greater chance of being victimized by violence compared to youth with fewer delinquent peers. Specifically, the x-axis shows a range of standardized values for the delinquent peer measure such that 0 is the average for the analysis sample and negative and positive values represent standard deviations above and below the mean. Values above the mean indicate more delinquent peers and those below represent fewer delinquent peers. The probability of violent victimization increases as a function of delinquent peers, with larger probabilities of violent victimization related to delinquent peer values above the mean and smaller probabilities of violent victimization related to delinquent peer values below the mean. For instance, youth scoring a -2 on the delinquent peers measure, i.e., having the fewest delinquent peers, had approximately a 21 percent chance of being victimized by violence at wave 2. Youth with a mean score on the delinquent peers measure, i.e., 0 , had approximately a 27 percent chance of being victimized by violence. Youth scoring a 4 on the delinquent peers measure, i.e., 


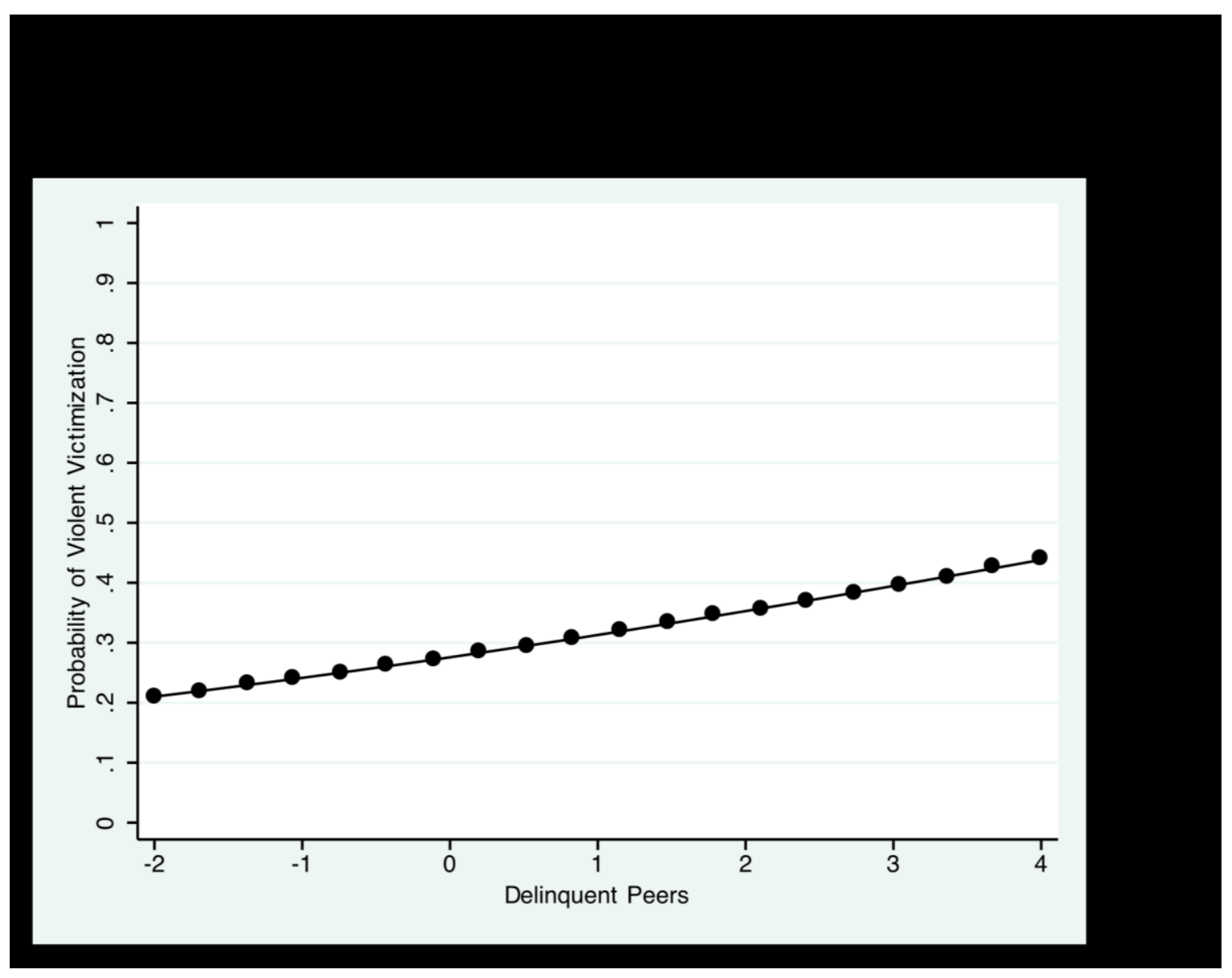

having the largest portion of delinquent peers, had approximately a 44 percent chance of being a victim of violence.

Fourth, Figure 3 shows that youth who spend more time in unstructured socializing activities with peers have a greater chance of being victimized by violence. The x-axis shows a range of standardized values for the unstructured socializing with peers measure such that 0 is the average for the analysis sample and negative and positive values represent standard deviations above and below the mean. Values above the mean indicate spending more time in unstructured socializing activities and those below represent less time in such activities with 


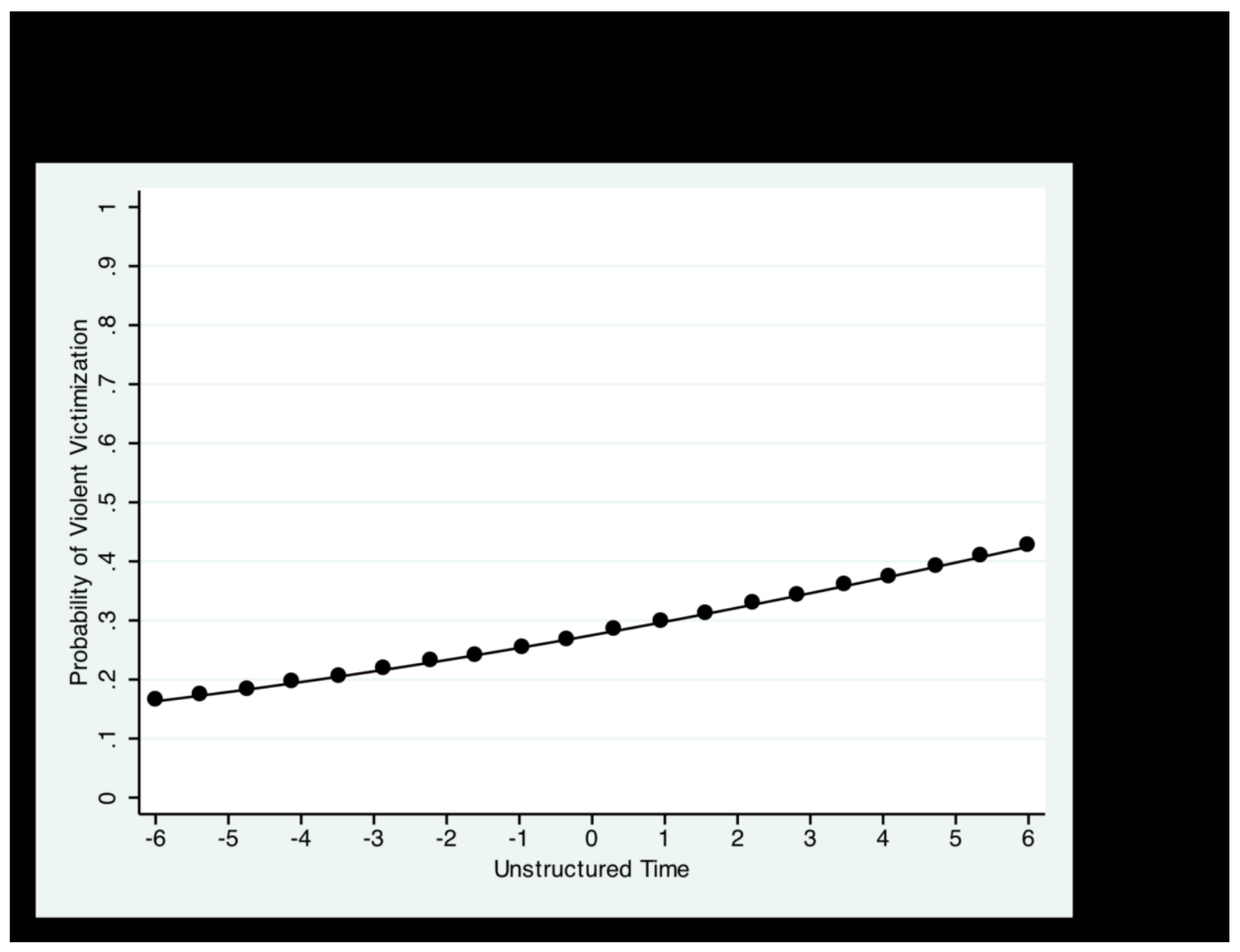

peers. The probability of violent victimization increases as a function of scores on the unstructured socializing measure, with larger probabilities of violent victimization related to scores above the mean and smaller probabilities of violent victimization related to scores below the mean. For instance, youth scoring a -3 on the unstructured socializing measure, i.e., 3 standard deviation units below the mean amount of unstructured socializing, had approximately a 22 percent chance of being victimized by violence. Youth at the mean on the unstructured socializing measure, i.e., 0 , had approximately a 27 percent chance of being victimized by violence. Youth scoring a 3 on the unstructured socializing measure, i.e., 3 standard 
deviation units above the mean amount of unstructured socializing, had approximately a 34 percent chance of being a victim of violence.

\section{Conditional Probabilities of Violent Victimization: Differing Influences of Low}

\section{Self-Control Across Neighborhood Concentrated Disadvantage}

This section reports the conditional predicted probabilities for violent victimization as a function of low self-control for youth living in the lowest and highest disadvantage neighborhoods while holding constant all demographic, family, and lifestyle variables from previous models. Figure 4 shows a range of standardized scores on the $\mathrm{x}$-axis indicating levels of self-control such that 0 is the average self-control score and negative and positive values represent standard deviations above and below the mean; those values above the mean indicate lower self-control and those below represent more self-control. Probabilities of violent victimization are shown on the y-axis.

The probability of violent victimization increases as a function of low selfcontrol scores. Youth with lower self-control (higher scores) had a greater chance of being victims of violence; although in the most disadvantaged neighborhoods the association between low self-control and violent victimization was not statistically significant. In the lowest disadvantaged neighborhoods the probabilities of violent victimization increase exponentially from a low to very high chance of violent victimization. In comparison, the probability of being victimized by violence across low self-control scores is not nearly as pronounced in the high disadvantaged neighborhoods and did not reach statistical significance. Second, even at the highest 


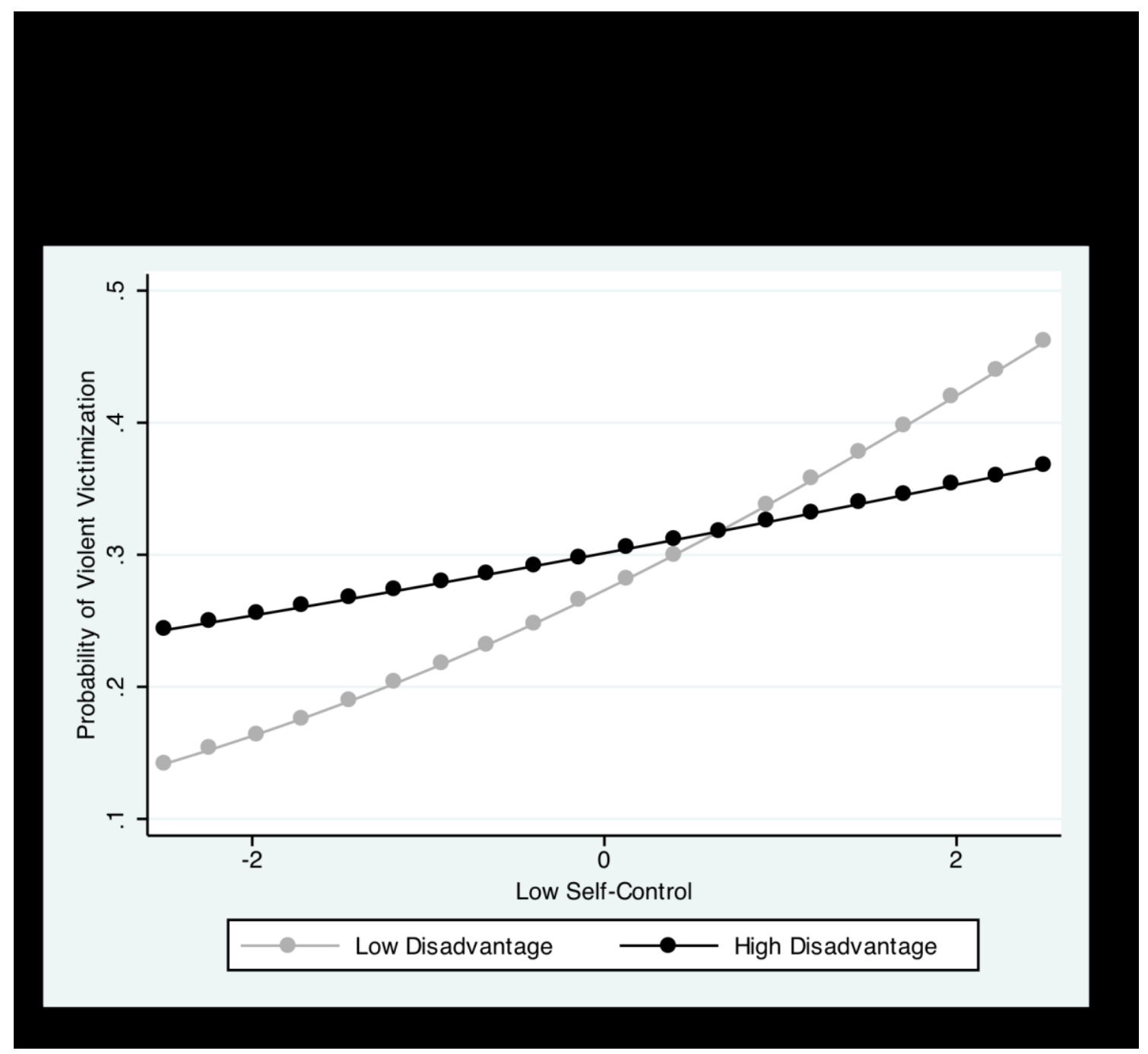

levels of self-control, it appears that the difference in violent victimization for those living in disadvantaged neighborhoods is nearly double the risk compared to those who live in the lowest disadvantaged neighborhoods. For instance, youth scoring a 2.5 on the low self-control measure, i.e., possessing the most self-control, have almost a 15 percent chance of being victimized by violence, but youth with a similar score on low self-control in the highest disadvantaged neighborhoods had almost a 25 percent chance of being victimized by violence. In contrast, youth living in the least disadvantaged neighborhoods and had the lowest self-control are at most risk 
for being violently victimized compared to those who had the lowest self-control in the most disadvantaged neighborhoods. In fact, youth scoring a 2.5 on the low selfcontrol measure, i.e., possessing the lowest amount of self-control, in the lowest disadvantaged neighborhoods had approximately a 45 percent chance of being a victim of violence compared to approximately a 35 percent chance of being a victim of violence for youth with the lowest self-control scores living in the most disadvantaged neighborhoods.

\section{CONCLUSIONS}

\section{Discussion of Findings}

Scholars and policy makers largely agree that residents of structurally disadvantaged neighborhoods, where conditions such as poverty, unemployment, and residential turnover are the norm, face major social and economic obstacles. Beyond the fact that crime is a part of everyday life in such neighborhoods, families face imposed structural forces that create barriers for social advancement that can often result in negative outcomes for them and their children (Leventhal \& BrooksGunn, 2003; Maimon \& Browning, 2010; Sampson et al., 2005; Sharkey, 2006). Ranging from health disparities to quality of life, and more generally life success, neighborhoods are contexts that can influence many aspects of people's lives.

The current study contributed to this body of literature by weaving together two strains of criminological research to better understand violent victimization experienced by youth living in different neighborhoods contexts. Results support 
the idea that these neighborhood and trait-based explanations should not be considered separately.

Four findings from this study are particularly noteworthy. First, findings from the current study confirm the work by Schreck and others (Schreck, 1999; Schreck et al., 2002; Higgins et al., 2010) by showing that children and adolescents with low self-control are independently at more risk for becoming victims of violence. More impressive is the fact that this relationship remained after controlling for situational, behavioral, and lifestyle characteristics that influence vulnerability to violent victimization, and are commonly chosen by low self-control individuals. Second, and running counter to research on neighborhoods and criminal victimization among adults, children and adolescents residing in the most disadvantaged neighborhoods are not significantly more likely to experience violent victimization compared to those in the lowest disadvantaged neighborhoods, although this relationship was in the hypothesized direction. Third, delinquent peers and prior involvement in violent offending had direct influences on violent victimization, but were importantly conditioned by neighborhood structural disadvantage; those who have more delinquent peers and report involvement in violent offending were significantly more at risk for becoming victims of violence, but only in the least disadvantaged neighborhoods. Finally, it was found that low self-control's influence on violent victimization was also conditioned by neighborhood structural disadvantage. Youth with lower self-control had an increased risk of violent victimization in the least disadvantaged neighborhoods; however, youth with lower self-control did not have a significantly increased risk of 
violent victimization in the most structurally disadvantaged neighborhoods. This finding appears to be consistent with Raine’s (2002) "social push" perspective.

To recap, the social push perspective implies that in disadvantaged and criminogenic environments more social pressure exists for individuals to engage in crime, violence, and other illegal activities. As such, individual differences in biologically related, trait-based variables will have less of an impact on antisocial and aggressive behavior because the environmental context overrides individual risk. While Raine $(1988 ; 2002)$ intended for this explanation to be specific to the influence of biological-based traits on antisocial outcomes, it is believed to be applicable to the measures and findings from the current study for two reasons. First, although Gottfredson and Hirschi (1990) theoretically argue that the development underpinnings of low self-control is largely determine by parental disciplining practices, recent empirical findings show that variation in low selfcontrol is partially explained by biological factors such as genetics (Beaver et al., 2008; Wright \& Beaver, 2005), making low self-control a trait that fits well under the social push framework. Second, given the strong overlap between violent offending and victimization (Lauritsen et al., 1991), and the studies that find similar characteristics that predict both (Jennings et al., 2010), it is not a stretch to make the leap from antisocial outcomes that Raine discusses (e.g., violence, conduct problems, etc.) to violent victimization risk.

Questions still remain as to why variation in violent victimization among children and adolescents from structurally disadvantaged neighborhoods is not significantly influenced by low self-control, and why youth who possess low self- 
control in the least disadvantaged neighborhoods do have an increased risk of becoming victims of violence. The amount of crime, proximity to offenders, and social and cultural processes occurring in disadvantaged neighborhoods may make children and adolescents more vulnerable to violence in such neighborhoods by overpowering the effects of individual differences. For instance, it is plausible to speculate that violent victimization risk is more similar for those living in neighborhoods with high crime rates where residents are less likely to look after youth. Given that structurally disadvantaged neighborhoods often lack community informal social controls and have elevated crime rates, it is not surprising that youth living in them are supervised more often by parents compared to those in less disadvantaged neighborhoods. However, parental supervision in this study does not seem reduce the risk of violent victimization.

Sub-cultural explanations are also plausible. Risk may be similar, regardless of individual differences, because youth with low and high self-control may face similar obstacles for attaining status and economic success (Kubrin \& Weitzer, 2003), which in turn may lead them to adopt unconventional ideals to gain status and respect. This can contribute to the emergence of values that encourage and violence or an "I will get them before they get me" mentality. Such sub-cultural values encourage hostile and aggressive consequences for those perceived to be disrespectful. In disadvantaged neighborhoods where such sub-cultural values are strong can systematically increase vulnerability to violent victimization and even make youth more aware of the need to use violence and exhibit aggression in attempts to avoid attacks and to gain respect (Anderson, 1999). As Anderson states 
(1999, p.33), street cultures that emerge in such neighborhoods provide a "rationale allowing those who are inclined to aggression to precipitate encounters in an approved way." Future research should explore these reasons for why individual differences in low self-control do not influence violent victimization risk in disadvantage neighborhoods.

This study does not provide a conclusive explanation as to why low selfcontrol influences violent victimization for adolescents residing in the least and moderately disadvantaged neighborhoods. As argued by Raine (2000), this could simply be because the social pressures found in the most disadvantaged contexts are less likely, non-existent, or attenuated in the least disadvantaged neighborhoods. It could also be that different social processes are operating in these neighborhoods leading to low self-control's influence on victimization to be more pronounced. Whatever the case, it will be left for future research to explore more deeply this finding.

\section{Implications for Policy and Practice}

Historically, adolescents have had the highest risk of becoming victims of violence. Much of the research that addresses prevention of violent victimization has tended to focus on lifestyle factors, routine activities (e.g., suitable targets and guardianship), and target hardening, but provides less focus on the interactive, multilayered context of risk. For example, strategies to change both neighborhood and individual factors may be important for reducing violent victimization risk among youth, yet researchers have rarely attempted to identify risk factors 
occurring at both levels for violent victimization in the same study (see Berg \& Loeber, 2011). Prevention and intervention efforts to curb violent victimization among youth should focus on identifying changeable individual-level factors with careful attention to the neighborhood environments that youth reside.

Findings from this study have several potential implications for reducing violent victimization risk among adolescents. Because low self-control has such far reaching influences on a spectrum of social and health-related outcomes over the life-course (Moffitt et al., 2011), it is important to identify early childhood precursors of low self-control to prevent the accumulation of negative outcomes that are often consequences of this trait, one of which is vulnerability to violence. From a theoretical perspective, Gottfredson and Hirschi are clear that prevention strategies targeting early socialization and parenting practices should improve selfcontrol, something that has not received much attention for the prevention of violent victimization, but has for delinquency and offending behaviors (Piquero, Jennings, \& Farrington, 2010).

While criminologists have investigated the effects of low self-control on numerous antisocial outcomes over the past decade and a half and have found support for the proposition that low self-control is an important predictor for child, adolescent and adult outcomes (Pratt \& Cullen, 2000), the same can not be said when it comes to policy and prevention efforts related to the development of selfcontrol. Criminologists have done little towards developing and evaluating programs that can assist in the development of healthy levels of self-control for children. In fact, only recently have criminologists begun to assess the malleability 
of self-control over time (Burt et al., 2006; Hay \& Forrest, 2006). Criminologists have investigated correlates and predictors of self-control that provide insights into what factors should be focused on for intervention purposes. These include parenting dimensions such as monitoring, disciplining and parental recognition of misbehavior in childhood. Some researchers have identified socialization efforts beyond the family such as neighborhood and school influences on children's selfcontrol (Gibson et al., 2010; Turner, Pratt, \& Piquero, 2002; Pratt, Turner, \& Piquero, 2004), and others have identified that self-control differences among youth are influenced by heritable genetic factors that are less susceptible to change (Wright \& Beaver, 2005). Criminologists know less about how these factors can be affectively manipulated and how targeted interventions that focus on the predictors of selfcontrol can lead to improvements in self-control for children and adolescents in the short and long-term.

Some investment, however, has been made outside the field of criminology to determine what programmatic efforts are effective for improving children's selfcontrol. In a recent study, Piquero and colleagues (2010) conducted a meta-analysis on 34 studies that systematically investigated the effectiveness of programs designed to improve self-control among children before the age of 10 , the age at which Gottfredson and Hirschi (1990) theorize self-control levels for children becomes fixed. Studies were selected for inclusion if they had a randomized controlled experimental research design and measured self-control (and delinquency or problems behaviors) during a post-test examination. Piquero and colleagues (2010: 8) concluded that "improvement programs are an effective 
intervention for improving self-control and reducing delinquency and problems behaviors, and that the effect of these programs appears to be rather robust across various weighting procedures, and across outcome source, and based on both published and unpublished data."

The self-control improvement programs reviewed by Piquero and colleagues (2010) varied with respect to the types of interventions and training delivered. They classified them into several categories. Some focused on the improvement of social skills by addressing improvement in communication skills; skills related to friendship and self-control; and problem solving techniques. Others involved treatment through role-playing interventions, immediate/delayed reward interventions, and relaxation training interventions (for a more thorough review see Piquero et al., 2010; 19-21).

It is yet to be determined whether intervention efforts are effective beyond the childhood years. Although early prevention is important (Piquero et al., 2010), promising research does suggests that self-control is plastic and is susceptible to change in later stages of one's life-course too (Burt et al., 2006; Moffitt et al., 2011; Roberts, Walton, \& Viecthbauer, 2006). As such, both unique and universal prevention and intervention efforts will be important to develop for targeting developmentally sensitive periods that teaches individuals to make informed decisions before acting; seriously consider how their actions affect others; and more generally teach them to think about the personal consequences of their own behavior. As Moffitt and colleagues (2011, p. 2967) stated, "early childhood intervention that enhances self-control is likely to bring a greater return on 
investment than harm reduction programs targeting adolescence alone." According to the present study's findings such efforts may be particularly important for those living in the least disadvantaged neighborhood environments.

This is not to say, however, that opportunities to intervene in the development of self-control among children in more disadvantaged neighborhoods is unimportant. In fact, PHDCN youth residing in more disadvantaged neighborhoods have been shown to have lower self-control than youth in less disadvantaged neighborhoods (Gibson et al., 2010) ${ }^{19}$. Given the broader negative consequences that can stem from this trait, it is equally important to improve selfcontrol among youth from structurally impoverished neighborhoods, especially since families residing in such neighborhoods may not have the resources to do so. It will also be important to identify and address the environmental forces that override the influence of low self-control on vulnerability to violent victimization in disadvantaged neighborhoods.

Finally, unstructured time spent with peers was the only factor that exhibited a statistically significant relationship with violent victimization risk across levels of neighborhood structural disadvantage. Parents in high, medium, and low structurally disadvantaged neighborhoods may have success at reducing their children's violent victimization by minimizing and monitoring the unstructured activities they engage in with peers.

\footnotetext{
${ }^{19}$ This relationship, however, became non-significant once individual-level variables such as race, gender, and parenting were statistically controlled.
}

This document is a research report submitted to the U.S. Department of Justice. This report has not been published by the Department. Opinions or points of view expressed are those of the author(s) and do not necessarily reflect the official position or policies of the U.S. Department of Justice. 


\section{Study Limitations and Future Research}

Several limitations of this study are noteworthy. First, the focus has been on children and adolescents residing in Chicago neighborhoods. Consequently, research is needed to understand if the findings reported herein can be replicated in other large cities. Second, this study was unable to determine which neighborhood social mechanisms help to understand why youth with low self-control are more at risk for violent victimization in some neighborhoods but not in others. This was due to the fact that cross-level interactions were unable to be estimated given the relatively small number of those who were violently victimized within neighborhoods. Future empirical research needs to be conducted on the theoretical mechanisms discussed earlier that may be driving the differences found.

Third, violent victimization was measured over a twelve-month period. This measure only captured current prevalence in that victims of violence were distinguished from non-victims if they reported one of several types of violent victimizations versus none at all. Unfortunately, due to the low number of repeat victims of violence and the lack of violent victimization measures across waves, the current study was unable to examine whether the same or a different pattern of findings emerges for youth who are repeat victims of violence.

Fourth, it should also be emphasized that this study relied exclusively on a self-report measure of violent victimization. This limitation is one that could be adressed in future studies by using multiple sources for measuring violent victimization including official reports on adult and juveniles. In doing so, a different 
picture could emerge regarding the variation of violent victimization across neighborhoods.

Fifth, this study did not explore a similar theoretical framework for understanding property victimization because such measures were unavailable in the PHDCN. However, if self-control theory is correct, then youth with lower selfcontrol should be at increased risk for being victims of property crime too (Schreck, 1999). Research should further explore the intersection between low self-control and neighborhood conditions by assessing the frequency and the persistence of violent and property victimization over time. It is also worth noting that future research should also investigate the distinction between types of violent victimization and the relationship between the victim and offender when trying to further understand the influences of neighborhood and trait based variables on violent victimization.

Sixth, the current study operated under the assumption that low self-control leads to violent victimization due to the fact that theory and empirical research suggests that this is the case; however, it may be that violent victimization experiences can influence self-control. As noted by a reviewer, youth who are victims of violence or repeat victims of violence may learn that self-control is not efficacious. The idea that victimization experiences can change one's level of selfcontrol over time through a learning process is an interesting one. To test this idea would require repeated measures of violent victimization and self-control for the same youth over time. Unfortunately, the measure of self-control used in the current study was measured only during wave 1 data collection. 
Seventh, while the current study did not find violent victimization to significant vary across neighborhoods, the analyses used to detect this was unable to capture neighborhood mobility among families and their children. Research shows that moving away from impoverished neighborhoods may have beneficial effects for families (see Leventhal \& Brooks-Gunn, 2003); thus the causal effect of neighborhoods on violent victimization can not be discounted until more rigorous methodological design are implemented. However, some studies show that living in highly disadvantaged neighborhoods can have lingering negative effects on children even after they move away from them (Sampson, Sharkey, \& Raudenbush, 2008). Exploring how moving out of impoverished neighborhoods will influence violent victimization among youth may have promise for not only understanding neighborhood effects on violent victimization, but may also help understand the influence of low self-control on violent victimization.

Finally, this study measured only one trait. Researchers should not only measure low self-control more extensively in future research through teacher, parent, observational, and self-reports, but they should also expand the range of trait-based individual differences to further explore the social push perspective as it relates to violent victimization. These limitations, combined with the research ideas stemming from them, set the stage for a modest research agenda that will allow criminologists to further understand how the intersection between neighborhoods and individual differences may jointly and independently help minimize youths vulnerability to violence and more specifically reduce their risk of violent victimization. 


\section{REFERENCES}

Anderson, E. (1999). Code of the street: Decency, violence, and the moral life of the inner city. New York, NY: W. W. Norton and Company.

Beaver, K. M., Wright, J. P., DeLisi, M., \& Vaughn, M. G. (2008). Genetic influence on the stability of low self-control: Results from a longitudinal sample of twins. Journal of Criminal Justice, 36, 478-485.

Berg, M., \& Loeber, R. (2011). Examining the neighborhood context of the violent offending-victimization relationship: A prospective victimization. Journal of Quantitative Criminology, 27, 427-451.

Bouchard, T.J. (2004). Genetic influence on human psychological traits. Current Directions in Psychological Science, 13, 148-151.

Burt, C.H, Simons, R.L., \& Simons, L.G. (2006). A longitudinal test of the effects of parenting and the stability of self-control: Negative evidence for the general theory of crime. Criminology, 44, 353-396.

Buss, A. H., \& Plomin, R. (1975). A temperament theory of personality development. New York, NY: Wiley.

Caldwell, B., \& Bradley, R. (1984). Home observation for measurement of the environment. Little Rock, AR: University of Arkansas.

Cohen, L., \& Felson, M. (1979). Social change and crime rate trends: A routine activities approach. American Sociological Review, 44, 588-608.

Eslinger, P. J., Flaherty-Craig, C. V., \& Benton, A. L. (2004). Developmental outcomes after prefrontal cortex damage. Brain Cognition, 55, 84-103. 
Felson, M. (1986). Linking criminal choices, routine activities, informal control, and criminal outcomes. In D. B. Cornish \& R. V. Clarke (Eds.), The reasoning criminal: Rational choice perspectives on offending (pp. 119-128). New York, NY: Springer-Verlag.

Felson, M. (1998). Crime and everyday life. Thousand Oaks, CA: Pine Forge.

Felson, R. B. (1984). Patterns of aggressive interaction. In A. Mummendey (Ed.), Social Psychology of Aggression: From Individual Behavior to Social Interaction (pp. 107-126). Berlin: Springer-Verlag.

Fisher, B. S., Sloan, J. J., Cullen, F. T., \& Lu, C. (1998). Crime in the ivory tower: The level and sources of student victimization. Criminology, 36, 671-710.

Gibson, C., Morris, S., \& Beaver, K. (2009). Secondary exposure to violence during adolescence: Does neighborhood context matter? Justice Quarterly, 26, 30-57.

Gibson, C., Sullivan, C., Jones, S., \& Piquero, A. (2007). Does it take a village? Assessing neighborhood effects on children's self-control. Journal of Research in Crime and Delinquency, 47, 31-62.

Gottfredson, M. R., \& Hirschi, T. (1990). A general theory of crime. Stanford, CA: Stanford University Press.

Grasmick, H. G., Tittle, C. R., Bursik, R. J., \& Arneklev, B. J. (1993). Testing the core implications of Gottfredson and Hirschi's general theory of crime. Journal of Research in Crime and Delinquency, 30, 5-29.

Hay, C., \& Forrest, W. (2006). The development of self-control: Examining self-control theory's stability thesis. Criminology, 44, 739-774.

Heckman, J. J. (2007). The economic, technology, and neuroscience of human capability 
formation. Proceedings of the National Academy of Sciences, 104, 13250-13255.

Higgins, G., Jennings, W., Tewksbury, R., \& Gibson, C. (2010). Exploring the link between low self-control and violent victimization trajectories. Criminal Justice and Behavior, 36, 1070-1084.

Hindelang, M. J., Gottfredson, M. R., \& Garofalo, J. (1978). Victims of Personal Crime: An Empirical Foundation for a Theory of Personal Victimization. Cambridge, MA: Ballinger.

Jacobs, B. A. \& Wright, R. (2006). Street justice: Retaliation in the criminal underworld. New York, NY: Cambridge.

Jennings, W.G., Higgins, G.E., Tewksbury, R., Gover, A.R., \& Piquero, A.R. (2010). A longitudinal assessment of the victim-offender overlap. Journal of Interpersonal Violence, 25, 2147-2174.

Jensen, G. F., \& Brownfield, D. (1986). Gender, lifestyles, and victimization: Beyond routine activity theory. Violence and Victims, 1, 85-99.

Kennedy, L. W., \& Forde, D. R. (1990). Routine activity and crime: An analysis of victimization in Canada. Criminology, 28, 137-152.

Kochanska, G., Coy, K. C., \& Murray, K. T. (2001). The development of self-regulation in the first four years of life. Child Development, 72, 1091-1111.

Kornhauser, R. (1978). Social sources of delinquency. Chicago, IL: University of Chicago Press.

Kubrin, C.E. \& Weitzer, R. (2003). New directions in social disorganization theory. Journal of Research in Crime and Delinquency, 40, 374-402. 
Lauritsen, J. L. (2001). The social ecology of violent victimization: Individual and contextual effects in the NCVS. Journal of Quantitative Criminology, 17, 3-32.

Lauritsen, J.L., \& Laub, J.H. (2007). Understanding the link between victimization and offending: New reflections on an old idea. Crime Prevention Studies, 22, 55-76.

Lauritsen, J. L., Laub, J. H., \& Sampson, R. J. (1992). Conventional and delinquent activities: Implications for the prevention of violent victimization among adolescents. Violence and Victims, 7, 91-108.

Lauritsen, J. L., Sampson, R. J., \& Laub, J. H. (1991). The link between offending and victimization among adolescents. Criminology, 29, 265-291.

Lee, M. R. (2000). Community cohesion and violent predatory victimization: A theoretical extension and cross-national test of opportunity theory. Social Forces, 79, 683-688.

Leventhal, T., \& Brooks-Gunn, J. (2000). The neighborhoods they live in: The effects of neighborhood residents on child and adolescent development. Psychological Bulletin, 126, 309-337.

Leventhal, T., \& Brooks-Gunn, J. (2003). Children and youth in neighborhood contexts. Current Directions in Psychological Science, 12, 27-31.

Leventhal, T., Selner-O’Hagan, M., Brooks-Gunn, J., Bingenheimer, J. B., \& Earls, F. (2004). The homelife interview from the project on human development in Chicago neighborhoods: Assessment of parenting and home environment for 3to15-year-olds. Parenting: Science and Practice, 4, 211-241.

Luckenbill, D. F. (1977). Criminal homicide as a situated transaction. Social Problems, 25, $176-186$.

This document is a research report submitted to the U.S. Department of Justice. This report has not been published by the Department. Opinions or points of view expressed are those of the author(s) and do not necessarily reflect the official position or policies of the U.S. Department of Justice. 
Lynam, D., Caspi, A, Moffitt, T., Wikstrom, P., Loeber, R., \& Novak, K. (2000). The interaction between impulsivity and neighborhood context on offending: The effects of impulsivity are stronger in poorer neighborhoods. Journal of Abnormal Psychology, 109, 563-574.

Maimon, D., \& Browning, C. (2010). Unstructured socializing, collective efficacy, and violent behavior among urban youth. Criminology, 48, 443-474.

Mayer, S., \& Jencks, C. (1989). Growing up in poor neighborhoods: How much does it matter? Science, 243, 1441-1445.

Miethe, T. D. \& D. McDowall. (1993). Contextual effects in models of criminal victimization. Social Forces, 71, 741-759.

Mischel, W. (1977). The interaction of person and situation. In D. Magnusson \& N. S. Endler (Eds.), Personality at the crossroads: Current issues in interactional psychology (pp. 33-352). Hillsdale, NJ: Erlbaum.

Moffitt, T. E., Arseneault, L., Belsky, D., Dickson, N., Hancox, R. J., Harrington, H., Houts, R., Poulton, R., Roberts, B. W., Ross, S., Sears, M., Thomson, M.S., \& Caspi, A. (2011). A gradient of childhood self-control predicts health, wealth, and public safety. Proceedings of the National Academy of Sciences, 108, 2693-2698.

Molnar, Buka, Brennan, Holton, \& Earls. (2003). A multilevel study of neighborhoods and parent-to-child physical aggression: Results from the project on human development in Chicago neighborhoods. Child Maltreatment, 8, 84-97.

Morenoff, J.D., Sampson, R.J., Raudenbush, S. (2001). Neighborhood inequality, collective efficacy, and the spatial dynamics of homicide. Criminology, 39, 517560. 
Osgood, D.W., \& Haynie, D.L. (2005). Reconsidering peers and delinquency: How do peers matter? Social Forces, 84, 1109-1130.

Osgood, D. W., Wilson, J., O’Mally, P., Bachman, J., \& Johnston, L. (1996). Routine activities and individual deviant behavior. American Sociological Review, 61, 635-655.

Piquero, A.R., Jennings, W.G., \& Farrington, D.P. (2010). Self-control interventions for kids under age 10 for improving self-control and delinquency and problem behaviors. Campbell Systematic Review, 2.

Pratt, T. C. \& Cullen, F. T. (2000). The empirical status of Gottfredson and Hirschi's general theory of crime: A meta-analysis. Criminology, 38, 931-964.

Pratt, T.C., Turner, M., \& Piquero, A.R. (2004). Parental socialization and community context: A longitudinal analysis of the structural sources of self-control. Journal of Research in Crime and Delinquency, 41, 219-243.

Raine, A. (1988). Antisocial behavior and psychophysiology. In H. L. Wagner (Ed.), Social psychophysiology and emotion: Theory and clinical application (pp. 231250). New York, NY: Wiley.

Raine, A. (2002). Biosocial studies of antisocial and violent behavior in children and adults. Journal of Abnormal Child Psychology, 30, 311-326.

Raudenbush, S. W. \& Sampson, R. J. (1999). "Ecometrics": Toward a science of assessing ecological settings, with application to the systematic social observation of neighborhoods. Sociological Methodology, 29, 1-41.

Rennison, C.M. (2002). Hispanic victims of violent crime. Bureau of Justice Statistics Special Report. NCJ 191208. 
Roberts, B. W., Walton, K.E., \& Viechtbauer, W. (2006). Patterns of mean-level change in personality traits across the life-course: A meta-analysis of longitudinal studies. Psychological Bulletin, 132, 1-25.

Sampson, R. J. (1983). Structural density and criminal victimization. Criminology, 21, 276-293.

Sampson, R. (1985). Neighborhood and crime: The structural determinants of personal victimization. Journal of Research in Crime and Delinquency, 22, 7-40.

Sampson, R. J. (2006). How does community context matter? Social mechanisms and the explanation of crime rates. In P. H. Wikstrom \& R. J. Sampson (Eds.), The explanation of crime: Context, mechanisms, and development (pp.31-60). Cambridge: Cambridge University Press.

Sampson, R.J., \& Groves, W.B. (1989). Community structure and crime: Testing SocialDisorganization theory. American Journal of Sociology, 94, 774-802.

Sampson, R. J., Morenoff, J., \& Earls, F. (1999). Beyond social capital: Spatial dynamics of collective efficacy for children. American Sociological Review, 64, 633-660.

Sampson, R. J., Morenoff, J. D., \& Raudenbush, S. (2005). Social anatomy of racial and ethnic disparities in violence. American Journal of Public Health, 95, 224-232.

Sampson, R. J., Raudenbush, S., \& Earls, F. (1997). Neighborhoods and violent crime: A multilevel study of collective efficacy. Science, 277, 918-924.

Sampson, R., Sharkey, P., \& Raudenbush, S. (2008). Durable effects of concentrated disadvantage on verbal ability among African-American children. Proceedings of the National Academy of Sciences, 105, 845-852. 
Sampson R., \& Wooldredge, J. (1987). Linking the micro and macro-level dimensions of lifestyle- routine activity and opportunity models of predatory victimization. Journal of Quantitative Criminology 3, 371-393.

Schreck, C. J. (1999). Criminal victimization and low self-control: An extension and test of a general theory of crime. Justice Quarterly, 16, 633-654.

Schreck, C. J., Fisher, B. S., \& Miller, J. M. (2004). The social context of violent victimization: A study of the delinquent peer effect. Justice Quarterly, 21, 23-48.

Schreck, C. J., Stewart, E. A., \& Fisher, B. S. (2006). Self-control, victimization, and their influence on risky activities and delinquent friends: A longitudinal analysis using panel data. Journal of Quantitative Criminology 22:319-340.

Schreck, C. J., Wright, R. A., \& Miller, J. M. (2002). A study of individual and situational antecedents of violent victimization. Justice Quarterly, 19, 159-180.

Sharkey, P. (2006). Navigating dangerous streets: The sources and consequences of street efficacy. American Sociological Review, 31, 826-846.

Shaw, C., \&McKay, H. (1942). Juvenile delinquency in urban areas. Chicago: University of Chicago Press.

Singer, S. (1981). Homogeneous victim-offender populations: A review and some research implications. Journal of Criminal Law and Criminology, 72, 779-788.

Stewart, E. A., Elifson, K., \& Sterk, C. (2004). Integrating the general theory of crime into an explanation of violent victimization among female offenders. Justice Quarterly, 21, 159-182.

This document is a research report submitted to the U.S. Department of Justice. This report has not been published by the Department. Opinions or points of view expressed are those of the author(s) and do not necessarily reflect the official position or policies of the U.S. Department of Justice. 
Stewart, E. A., Schreck, C. J., \& Simons, R. L. (2006). I ain't gonna let no one disrespect me: Does the code of the streets increase or reduce violent victimization. Journal of Research in Crime and Delinquency, 43, 427-458.

Thompson, C. Y. \& Fisher, B. S. (1996). Predicting household victimization utilizing a multi-level routine activity approach. Journal of Crime and Justice, 19, 49-66.

Tittle, C.R., Ward, D.A., Grasmick, H.G. (2003). Self-control and crime/deviance: Cognitive vs. behavioral measures. Journal of Quantitative Criminology, 19, 333365.

Tunrer, M.G., \& Piquero, A.R. (2002). The stability of self-control. Journal of Criminal Justice, 30, 457-471.

Turner, M.G., Pratt, T.C., \& Piquero, A.R. (2005). The school context as a source of selfcontrol. Journal of Criminal Justice, 33, 329-339.

Velez, M.B. (2001). The role of public control in urban neighborhoods: A multi-level analysis of victimization risk. Criminology, 39, 837-864.

Von Henting, H. (1941). Remarks on the interaction of perpetrator and victim. Journal of Criminal Law, Criminology, and Political Science, 31, 303-309.

Ward, J.T., Gibson, C., Boman, J., \& Leite, W.L. (2010). "Is the general theory of crime really stronger than the evidence suggests? Assessing the validity of the retrospective behavioral self-control scale.” Criminal Justice and Behavior, 37, $336-357$.

Warner, B., \& Wilcox Rountree, P. (1997). Local social ties in a community and crime model: Questioning systemic nature of informal social control. Social Problems, $44,523-539$. 
Wilcox, P., Land, K. C., \& Hunt, S. (2003). Criminal circumstance: A dynamic, multicontextual criminal opportunity theory. New York, NY: Aldyne de Gruyter.

Wilcox-Rountree, P., Land, K. C., \& Miethe, T. D. (1994). Macro-micro integration in the study of victimization: A hierarchical logistic model analysis across Seattle neighborhoods. Criminology, 32, 387-414.

Wolfgang, M. (1958). Patterns in criminal homicide. New York, NY: John Wiley \& Sons.

Wright, J., \& Beaver, K. (2005). Do parents matter in creating self-control in their children? A genetically informed test of Gottfredson and Hirschi's theory of low self-control." Criminology, 43, 1169-120. 


\section{DISSEMINATION OF RESEARCH FINDINGS}

\section{Publications}

Gibson, Chris L. (in press) "An investigation of neighborhood context, low selfcontrol, and violent victimization among youth." Youth Violence and Juvenile Justice.

\section{Presentations}

Gibson, Chris L. (2011). "The influence of neighborhood context and antisocial propensity on violent victimization of children and adolescents in Chicago." Poster presented at the National Institute of Justice Conference, Arlington, VA.

Gibson, Chris L, Schreck, C, \& Stewart, E.A. (2011). "Neighborhoods, traits, and violent victimization: A longitudinal study of Chicago youth." Presented at the American Society of Criminology, San Francisco.

Gibson, Chris L. (2010). “The Influence of Neighborhood Context and Antisocial Propensities on Personal Victimization Experiences among Adolescents." Presented at the International Family Violence and Child Victimization Research Conference, Portsmouth, NH.

\section{Additional Research Dissemination Efforts}

As part of this NIJ funded research, I have embarked upon a larger dissemination project as a guest editor of a special issue in Youth Violence and Juvenile Justice titled "The Interplay between Neighborhood and Individual Factors in the Explanation of Delinquency Victimization, and Related Outcomes." This issue has a set publication date for early 2012 .

This project not only includes a manuscript which discusses findings from my current project but also incorporates studies from two other projects funded under the same NIJ funding stream that uses data from the Project on Human Development in Chicago Neighborhoods. The table of contents can be found below (asterisks indicate studies that were funded by the NIJ).

SOCIAL ADVERSITY, GENETIC VARIATION, STREET CODE, AND AGGRESSION: A GENETICLLY INFORMED MODEL OF VIOLENT BEHAVIOR

Ronald L. Simons, Man-Kit Lei, Eric A. Stewart, Gene Brody, Steven H. Beach, Robert A. Philibert, and Frederick X. Gibbons

THE INTERACTION BETWEEN NEIGBROHOOD DISADVANTAGE AND GENETIC FACTORS IN THE PREDICTION OF ANTISOCIAL OUTCOMES

Kevin M. Beaver, Chris L. Gibson, Matt DeLisi, Michael Vaughn, and John P. Wright 
*AN INVESTIGATION OF NEIGHBORHOOD CONTEXT, LOW SELF-CONTROL, AND VIOLENT VICITMIZATION AMONG YOUTH

Chris L. Gibson

*THE EFFECTS OF NEIGHBORHOOD CONTEXT ON YOUTH VIOLENCE AND DELINQUENCY: DOES GENDER MATTER?

Abigail A. Fagan and Emily M. Wright

PROTECTION FROM RISK: AN EXPLANATION OF WHEN AND HOW NEIGBROHOOD-LEVEL FACTORS CAN REDUCE VIOELNT YOUTH OUTCOMES

Megan C. Kurlycheck, Marvin D. Krohn, Beidi Dong, Gina Penly Hall, and Alan J. Lizotte

*DEVELOPMENTAL ASSETS OF EMOTIONAL RESELIENCE AMONG YOUTH EXPOSED TO

COMMUNITY VIOLENCE: A PROSPECTIVE STRENGTHS-BASED STUDY

Sonia Jane, Stephen L. Buka, S.V. Subramanian, and Beth E. Molnar

Finally, two additional manuscripts are being planned related to this project, one for a trade journal and the other for an academic journal. 


\section{APPENDIX}

\section{Neighborhood Structural Variable}

\section{Concentrated Disadvantage}

Percentage of neighborhood residents below the poverty line

Percentage on public assistance

Percentage of female-headed families

Percentage unemployed

Density of children by percentage younger than 18

Percentage African-American

\section{Neighborhood Social Process Measures}

Intergenerational Closure

Parents know their children's friends

Adults know who local children are

Children look up to adults in neighborhood

Parents generally know each other

Adults watch out for children

Reciprocated Exchange

How often do people do favors for each other

How often do you have parties

How often do you watch others property

How often do visit each others homes

How often do you ask advice of neighbors

\section{Child-Centered Social Control}

Neighbors do something about kids skipping school

Neighbors do something about kids defacing building

Neighbors scold child not showing respect

\section{Low Self-Control}

Inhibitory Control

Has trouble controlling his/her impulses

Usually can not stand waiting 
Can tolerate frustration better than most (reverse coded)

Has trouble resisting temptation

Finds self-control easy to learn (reverse coded)

\section{Decision Time}

Often says the first thing that comes into his/her head

Likes to plan things way ahead of time (reverse coded)

Often acts on the spur of the moment

Always likes to make detailed plans before (s)he does something (reverse coded)

\section{Sensation Seeking}

Generally seeks new and exciting experiences and sensations

Will try anything once

Sometimes does "crazy" things just to be different

Tends to get bored easily

\section{Persistence}

Generally likes to see things through to the end (reverse coded)

Tends to give up easily

Unfinished tasks really bother (reverse coded)

Once gets going on something (s)he hates to stop (reverse coded)

\section{Parenting Measures}

\section{Parental Warmth}

Parent talks with child twice during visit

Parent answers child's questions orally

Parent encourages child to contribute

Parent mentions skill of child

Parent praises child twice during visit

Parent uses diminutive for child's name

Parent voices positive feelings to child

Parent caresses, kisses, or hugs child

Parent responds positively to praise of child

\section{Lack of Hostility}

Parent does not shout at child during visit

Parent does not express annoyance with child

Parent does not slap or spank child

Parent does not scold or criticize child 


\section{Supervision}

Subjects has a set time (curfew) to be home on school nights

Subjects has a set time (curfew) to be home on weekend nights

Has established rules about homework and checks to see if homework is done

Requires subject to sleep at home on school nights

When primary caregiver is not at home, reasonable procedures are established for

subject

to check in with primary caregiver or other designee on weekends or after school

After school subject goes somewhere that adult supervision is provided

Establishes rules for behavior with peers and asks questions to determine whether

they

are being followed

Subject is not allowed to wander in public places without adult supervision for more than three hours

Has had contact with two of the subject's friends in the last two weeks

Has visited with school or talked to the teacher or counselor within the last three months

Has discussed hazard of alcohol and drug abuse with subject in past year

Denies subject access to alcohol (including beer and wine in the home)

Know signs of drug use and remain alert to possible type or experimentation

\section{Family Support}

Family will always be there for me

Sometimes not sure if I can rely on family (reverse coded)

Family tells me they think I am valuable

Family had confidence in me

Family helps me find solutions to problems

Family will always stand by me

\section{Unstructured Activities with Peers}

Ride in car/motorcycle for fun

Hanging out with friends

Going to parties/social affairs

Number of day per week you go out at night/afterschool

\section{Violent Offending}

Have you ever:

Carried a weapon

Purposely set fire to a house, car, or vacant building

Snatched someone's purse or wallet 
Hit someone you live with

Hit someone you did not live with

Attack someone with a weapon

Use a weapon or force to get money or thing from people

Thrown object like rocks or bottles at people

Shot someone

Shot at someone

Been in a gang fight

Threatened to physically hurt someone

\section{Delinquent Peers}

In the past year, how many people you spend time with have done the following things:

Purposely damaged or destroyed property

Stolen something worth $\$ 5$ or less

Stolen Something worth $\$ 5$ but less than $\$ 500$

Stolen something worth more than $\$ 500$

Go into building and steal something

Taken a motor vehicle, car or motorcycle for a ride or drive without the owners permission

Gotten into a physical fight (fist) with schoolmates/coworker or friends

Hit someone with the idea of hurting them

Attacked someone with a weapon with the idea of seriously hurting them

Have used a weapon or force to get money or thing from people

Sold drugs, such as heroin cocaine, crack or LSD (other than marijuana) 